\title{
ESTABILIDADE FENOTÍPICA DE CULTIVARES DE ALGODOEIRO HERBÁCEO EM DIFERENTES SISTEMAS DE PRODUÇÃO NO ESTADO DO MATO GROSSO
}

\author{
EULALIA SOLER SOBREIRA HOOGERHEIDE
}

Dissertação apresentada à Escola Superior de Agricultura "Luiz de Queiroz", Universidade de São Paulo, para obtenção do título de Mestre em Agronomia, Área de Concentração: Genética e Melhoramento de Plantas.

P I R A C I C A B A

Estado de São Paulo - Brasil

Agosto - 2004 


\section{ESTABILIDADE FENOTÍPICA DE CULTIVARES DE ALGODOEIRO HERBÁCEO EM DIFERENTES SISTEMAS DE PRODUÇÃO NO ESTADO DO MATO GROSSO}

\section{EULALIA SOLER SOBREIRA HOOGERHEIDE}

Engenheiro Agrônomo

Orientador: Prof. Dr. ISAIAS OLÍVIO GERALDI

Dissertação apresentada à Escola Superior de Agricultura "Luiz de Queiroz", Universidade de São Paulo, para obtenção do título de Mestre em Agronomia, Área de Concentração: Genética e Melhoramento de Plantas.

PIR A C I C A B A

Estado de São Paulo - Brasil

Agosto - 2004 


\section{Dados Internacionais de Catalogação na Publicação (CIP) DIVISÃO DE BIBLIOTECA E DOCUMENTAÇÃO - ESALQ/USP}

Hoogerheide, Eulalia Soler

Estabilidade fenotípica de cultivares de algodoeiro herbáceo em diferentes sistemas de produção no Estado do Mato Grosso / Eulalia Soler Hoogerheide. - - Piracicaba, 2004.

$80 \mathrm{p}$.

Dissertação (mestrado) - - Escola Superior de Agricultura Luiz de Queiroz, 2004.

Bibliografia.

1. Algodão 2. Estabilidade fenotípica 3. Interação genótipo-ambiente 4. Melhoramento genético vegetal 5 . Sistema de produção I. Título

CDD 633.51 
Aos meus pais Pedro e Ascencion por tudo que fizerem por mim

Ao meu amado esposo Haroldo pela compreensão e amor

A minha querida irmã Eunice, pela constante amizade

\section{DEDICO}

A Jesus Cristo o Filho de Deus que me amou dando sua vida por mim numa cruz, para que eu e todo aquele que $\mathcal{N}$ ele crer, tivesse vida eterna. "Pois que aproveitaria ao homem ganfar o mundo inteiro, $e$ perder a sua alma?"(Mc 8:36)

OFEREÇO 


\section{AGRADECIMENTOS}

Agradeço a todos que estiveram relacionados direta ou indiretamente a execução desse trabalho.

Aos amados irmãos da Igreja Batista Nova Vida de Piracicaba, que foram a minha família neste período, como a Tetê, Milze, Regina, Márcio, Rosa... e em especial aos queridos pastores Marcílio e Sônia Guerra e à minha amada líder Elaine Lages. À pastora Lia, que me incentivou a iniciar esta jornada.

Aos funcionários do Departamento de Genética, às zeladoras, professores, Léia, Glória, Fernandinho, Berdã e Seu Vítor.

Aos meus colegas de curso, Gisa, Marinês, Luciana Cursino, Vandeco, Fernando, Bira, Rudimar, Edgard, e tantos outros, e em especial ao amigo Farias, o meu muito obrigado, pois foi um incentivador constante, usado por Deus para abençoar a minha vida.

À Embrapa-Algodão pelos dados cedidos para execução desta pesquisa e ao IAC pela montagem dos experimentos.

Ao pesquisador da EMPAER-MT Eurípedes Maximiano Arantes pelo envio dos dados da agricultura familiar.

Ao meu orientador Isaias Olívio Geraldi.

A CAPES pela concessão de bolsa de estudo. 


\section{SUMÁRIO}

\section{RESUMO}

\section{SUMMARY}

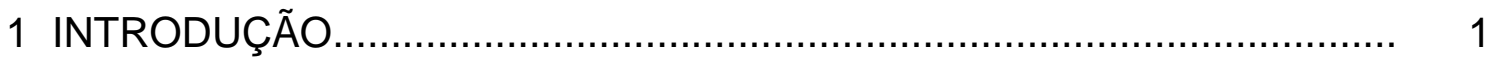

2 REVISÃO DE LITERATURA ........................................................ 3

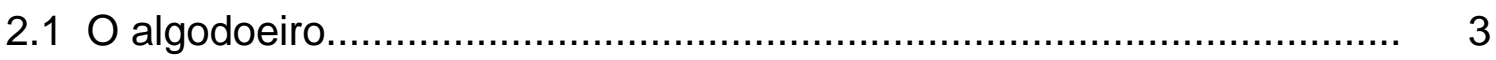

2.2 O melhoramento do algodoeiro no Brasil................................................. 4

2.3 Interação cultivares $x$ ambientes...................................................... 6

2.4 Estabilidade e adaptabilidade de cultivares....................................... 10

2.4.1 Conceitos básicos................................................................... 10

2.4.2 Principais metodologias........................................................... 14

2.4.3 Estudos de estabilidade no algodoeiro............................................ 21

3 MATERIAL E MÉTODOS................................................................ 23

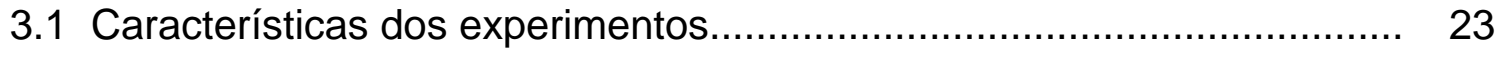

3.2 Análises estatísticas......................................................................... 28

3.2.1 Análises de variância.............................................................. 28

3.2.2 Análise de adaptabilidade e estabilidade fenotípica........................... 30

4 RESULTADOS E DISCUSSÃO....................................................... 33

4.1 Análise de variância individual........................................................... 34

4.2 Análises de variâncias conjuntas..................................................... 35

4.3 Adaptabilidade e estabilidade ........................................................ 39

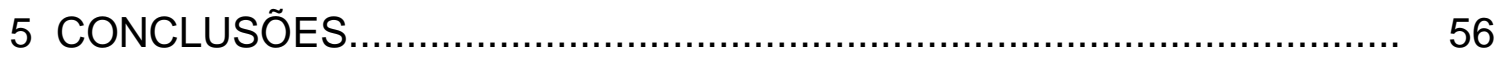

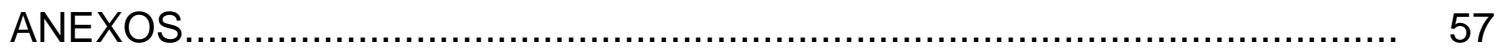

REFERÊNCIAS BIBLIOGRÁFICAS ................................................... 70 


\title{
ESTABILIDADE FENOTIÍPICA DE CULTIVARES DE ALGODOEIRO HERBÁCEO EM DIFERENTES SISTEMAS DE PRODUÇÃO NO ESTADO DO MATO GROSSO
}

\author{
Autora: EULÁLIA SOLER SOBREIRA HOOGERHEIDE \\ Orientador: Prof. Dr. ISAIAS OLÍVIO GERALDI
}

\section{RESUMO}

No estado do Mato Grosso o cultivo do algodão herbáceo ocorre em diferentes condições edafoclimáticas e sob dois sistemas de produção: o sistema empresarial que compreende grandes áreas (entre 100 e 5.000 ha) com uso intensivo de insumos e mecanização, e o sistema familiar caracterizado por pequenas áreas (até $5 \mathrm{ha}$ ), menor quantidade de insumos e uso de mão-de-obra familiar. O objetivo deste trabalho foi avaliar a magnitude da interação entre cultivares e locais, o componente predominante da interação (simples ou complexa) e a estabilidade e adaptabilidade fenotípica para o caráter produção de algodão em caroço, nos dois sistemas de produção, através da metodologia de Eberhart e Russell (1966). Os experimentos foram constituídos por 28 cultivares avaliados no delineamento em blocos ao acaso com quatro repetições, em 19 municípios do Estado do Mato Grosso, em três anos agrícolas: 1998/99, 1999/00 e 2000/01. Verificou-se que a ocorrência 
predominante da interação foi o complexo. Os cultivares ideais, caracterizados por maior produtividade, estabilidade e adaptabilidade ampla $(b=1)$ foram IAC/96-319, CNPA 96/1202, ITA-96, ANTARES, FMT-SATURNO e IPR-94 para o sistema empresarial; e EPAMIG PREC-1, CNPA-7H, IAC 97-86 e IPR-96 para o sistema familiar, em 1998/99, 1999/00 e 2000/01, respectivamente, indicando, também, a ocorrência de interação entre cultivares e sistemas de produção. Conseqüentemente, a avaliação de cultivares do programa de melhoramento do algodoeiro deve adotar critérios específicos para cada sistema de produção, empresarial ou familiar. 


\title{
PHENOTYPIC STABILITY OF COTTON CULTIVARS UNDER DIFFERENT PRODUCTION SYSTEMS IN THE MATO GROSSO STATE, BRAZIL
}

\author{
Author: EULALIA SOLER SOBREIRA HOOGERHEIDE \\ Adviser: Prof. Dr. ISAIAS OLÍVIO GERALDI
}

\section{SUMMARY}

In the state of Mato Grosso, cotton is grown under different environmental conditions and two production systems: the high input system in large areas (100 to 5,000 ha), and the low input system in small areas (up to 5 ha), where only the family labor is used. The objective of this research was to evaluate the magnitude of the cultivar by location interaction, the main component of the interaction (simple or complex) and the phenotypic stability and adaptability for the trait cotton seed yield for both systems, based on Eberhart \& Russell (1966)'s method. The yield trials were carried out in 19 locations of the Mato Grosso state, across three crop seasons: 1998/99, 1999/00 and 2000/01. Each experiment consisted of 28 cultivars, evaluated in a randomized block design with four replications. Cultivar by location interaction was detected for the three crop seasons, while the complex component explained most of this interaction, since the cultivar performances were not 
consistent over different locations. The best cultivars, characterized by higher yield, stability and broad adaptability $(b=1)$, were IAC/96-319, CNPA 96/1202, ITA-96, ANTARES, FMT-SATURNO and IPR-94 under the high input system and EPAMIG PREC-1, CNPA-7H, IAC 97-86 and IPR-96 under the low input system, respectively for 1998/99, 1999/00 e 2000/01 crop seasons, indicating the occurrence of cultivar by production system interaction as well. Consequently, the evaluation of cultivars in cotton breeding programs must take into account the two production systems, with specific criteria for each one of them. 


\section{INTRODUÇÃo}

O algodoeiro produz a mais importante fibra têxtil do mundo e é a segunda maior fonte de óleo vegetal. Esta espécie presta uma significante contribuição à economia brasileira, sendo cultivada em dezesseis estados, cobrindo uma área de 670.000 ha, movimentando o negócio de 30 mil empresas, responsáveis por 1,45 milhões de empregos diretos e faturamento anual de U\$ 22 bilhões (safra 2002) (Ampa, 2003).

Os avanços tecnológicos têm permitido aos produtores brasileiros alcançar incomparável eficiência nos últimos anos. Grande parte desse aumento pode ser atribuída ao melhoramento genético, sobretudo àqueles efetuados para as condições do Estado do Mato Grosso, onde a cultura de algodão apresentou um crescimento extraordinário na última década, saltando de 4\% para 50\% da produção nacional (Moresco, 2003).

A cultura do algodão encontra neste estado condição favorável para o seu desenvolvimento, o que faz melhorar a qualidade da pluma (Richetti e Melo Filho, 1998). O apoio dos produtores à pesquisa no Estado do Mato Grosso e a concentração de programas de desenvolvimento de cultivares na região têm sido os principais fatores de crescimento da produtividade e sustentabilidade da cultura (Moresco, 2003). 
O cultivo do algodão na região do Mato Grosso ocorre sob diferentes condições ambientais e também sob diferentes sistemas produção; devido a isso é de se esperar que haja interação entre cultivares e ambientes. Essas interações são de grande importância para caracteres quantitativos, como produtividade, que são bastante influenciados pelo ambiente (Farias et al., 1996).

No entanto, estudos da interação entre cultivares e ambientes não proporcionam informações pormenorizadas sobre o comportamento de cultivares frente às variações ambientais. Faz-se necessário realizar análises de adaptabilidade e estabilidade, pelas quais se torna possível a identificação de cultivares de comportamento previsível e que seja responsivo às variações ambientais, em condições específicas ou amplas, e assim fazer recomendação de cultivares com bastante critério (Cruz \& Regazzi, 2001).

A Embrapa-Algodão desenvolve trabalhos de melhoramento genético do algodoeiro no Estado do Mato Grosso para os sistemas de agricultura empresarial e familiar desde 1989, o que torna um estudo da estabilidade e adaptabilidade uma alternativa adequada para auxiliar o melhorista na recomendação dos cultivares disponíveis (Embrapa, 2003).

O objetivo deste trabalho foi avaliar a estabilidade e adaptabilidade de cultivares de algodoeiro, a magnitude e componente da interação entre cultivares e locais, nos anos agrícolas de 1998/99, 1999/00 e 2000/01 no Estado do Mato Grosso, sob dois sistemas de produção: empresarial e familiar. 


\section{REVISÃO DE LITERATURA}

\subsection{0 algodoeiro}

O algodoeiro (Gossypium hirsutum L.), denominado de algodão anual ou herbáceo é uma das quatro espécies cultivadas mundialmente para produzir fibra de algodão (Lee, 1984). Esta espécie é explorada em grandes áreas nas regiões tropicais e subtropicais, é responsável por 90\% da produção mundial, e tem grande importância social no Brasil. O produto colhido é denominado algodão em caroço e é composto pela pluma (fibra) e pelo caroço. A fibra é utilizada na indústria de fiação e o caroço na alimentação animal e humana. Nessa espécie o comprimento da fibra varia de média a longa (25,4 a 34,9 mm) (Fuzzato, 1999).

O algodoeiro é uma planta dicotiledônea, pertencente à família das Malváceas. O gênero Gossypium ao qual pertence, é bastante variado e segundo Fryxell (1992), conta com mais de 50 espécies que se propagam por sementes. Esse germoplasma pode ser dividido em: a) espécies selvagens e espécies cultivadas; b) espécies diplóides $(2 n=2 x=26)$ e espécies tetraplóides $(2 n=4 x=52) ;$ e c) espécies produtoras e espécies não produtoras de fibra fiável (Fuzatto, 1999). 
Esta espécie possui um sistema reprodutivo considerado misto (Allard, 1960). Possui flores hermafroditas, sendo a taxa de cruzamento natural variável, dependendo das condições ambientais, da presença dos agentes polinizadores e dos cultivares (Santos \& Freire, 1980). Já foram encontradas taxa de polinização de $0,28 \%$ a $100 \%$ (Mangueira, 1971). Assim torna-se possível à utilização de metodologias tanto de espécies autógamas quanto de alógamas para o seu melhoramento (Penna, 1999).

\subsection{O melhoramento do algodoeiro no Brasil}

O programa de melhoramento do algodão no Brasil iniciou em 1924, com a criação da Seção do Algodão do Instituto Agronômico de Campinas (IAC), com contribuição significativa do melhorista americano Dr. Sydney Cross Harland a partir de 1935, com ênfase para maior produtividade e melhoria no manejo (Cavaleri \& Gridi-Papp, 1993).

Na década de 1940 buscou-se melhoramento para os caracteres tecnológicos da fibra. Na década de 1950 e 1960 buscou-se resistência às doenças fusariose e murcha de fusarium. Na década de 1970, devido à evolução significativa da indústria têxtil, exigiu-se materiais com maior uniformidade e resistência de fibra e mais produtivos (Griddi-Papp et al., 1985).

A cultura do algodão no Estado do Mato Grosso teve seu início em 1933 com a chegada do Dr. Liberato Barrozo, trazendo $1.200 \mathrm{~kg}$ de sementes melhoradas do algodão herbáceo cultivar TEXAS 7111. Outros 
empreendedores na região da cidade de Rondonópolis contribuíram para a expansão dessa cultura, sendo tal cidade conhecida na época como rainha do algodão do Mato Grosso (Paro, 1992)

Na década de 1980 a Embrapa iniciou os estudos de adaptação e desenvolvimento de novos cultivares específicos para o Mato Grosso para os sistemas de produção empresarial e familiar (Embrapa, 2003).

A agricultura familiar do Estado do Mato Grosso é caracterizada por proprietários ou posseiros que utilizam implementos manuais, tração animal, ou contratam serviços para o preparo de solo; raramente utilizam adubação, fazem uso de mão-de-obra familiar e cultivam aproximadamente 5 a 6 hectares. Os produtores empresariais assemelham-se mais com empreendedores agroindustriais. Possuem propriedades com grandes áreas, mecanizam todas as etapas da lavoura, inclusive a colheita do algodão. Em sua maioria comercializam a pluma e a semente diretamente junto às indústrias têxteis e de óleo, exigindo cultivares com alto rendimento de pluma e com características tecnológicas dentro dos padrões exigidos pelas indústrias (Freire et al., 2001).

O rápido crescimento da cotonicultura mecanizada e altamente empresarial, juntamente com a implementação da lei de proteção de cultivares em 1997, despertaram o interesse das grandes empresas estrangeiras em trazer para o Brasil seus programas de pesquisa na área de melhoramento genético de algodão. Como exemplo disso atuam atualmente no Brasil inúmeras empresas privadas: Delta Pine Land Company, Stoneville, Syngenta Seeds, Aventis Seeds, CIRAD - em parceria com a Coodetec. 
Além disso diversos programas de melhoramento vem sendo conduzidos por instituições públicas, como o Instituto Agronômico de Campinas (IAC) em São Paulo; IAPAR, no Paraná e a EPAMIG em Minas Gerais; empresas privadas também estão presentes através de suas Fundações (Anuário Brasileiro do Algodão, 2001).

De maneira geral, os objetivos dos programas de melhoramento de algodão no cerrado são: alta produtividade, alto rendimento de fibras, características tecnológicas modernas para as fibras medidas nos aparelhos HVI (high volume instrument), incluindo obtenção de fibras mais finas, resistentes e uniformes (Freire, 2001).

Nos programas melhoramento do Centro-Oeste busca-se ainda cultivares com resistência múltipla às doenças (ramulose, viroses, ramularia, mancha de Alternaria e bacteriose), às pragas (pulgões e lepdópteros), adaptadas aos cerrados (regiões de altitude, solos ácidos e de alta precipitação) e às operações mecanizadas, como colheita mecânica (Freire \& Costa, 1999).

\subsection{Interação entre cultivares e ambientes}

Quando vários cultivares são avaliados em vários ambientes, pode ocorrer de o ambiente afetar de modo diferente o mesmo caráter em diferentes cultivares, ou seja, pode ocorrer uma interação entre os dois fatores. Define-se, então, a interação entre cultivares e ambientes, como sendo o efeito residual da resposta diferencial dos ambientes sobre os cultivares. Vista por outro lado, a 
interação resulta da resposta diferencial dos cultivares as variações ambientais (Chaves, 2001).

Como ambiente entende-se uma série de condições em que as plantas se desenvolvem, que podem envolver anos, locais, regiões, época de cultivo, manejo, ou ainda a combinação de todos esses fatores (Romagosa \& Fox, 1993 citado por Rocha, 2002). Segundo Cruz \& Carneiro (2003) as causas da interação entre cultivares e ambientes podem ser atribuídos a fatores fisiológicos, adaptativos e relativos à escala de mensuração das variáveis, entre outros.

Allard e Bradshaw (1964) classificam as variações ambientais que contribuem para a interação em previsíveis e imprevisíveis. Nas previsíveis estão incluídos os fatores permanentes do ambiente, como as características gerais do clima e do tipo de solo, e características do ambiente, que variam de maneira sistemática, como fotoperíodo. Inclui também aqueles que o homem atua de forma direta como época de plantio, tipo de adubação e métodos de colheita. As variações imprevisíveis são as que incluem as flutuações variáveis do ambiente, como precipitações, temperatura, umidade relativa, geadas, veranicos.

Falconer (1987) comenta que o significado da interação cultivar x ambiente é uma fonte de variação dos valores fenotípicos, que na maioria das análises, é inseparável da variância de ambiente. Na prática, para se detectar a interação cultivares e ambientes, faz-se necessário que um mesmo experimento seja repetido em vários ambientes. Crossa (1990) comenta que se o experimento é realizado em apenas um ambiente, pode ocorrer uma 
superestimação dos ganhos genéticos, e se a interação for do tipo complexa, a recomendação de cultivares para ambientes diferentes daqueles onde foram selecionados, poderá contribuir para a redução do ganho com a seleção.

Para se detectar a interação, os diferentes cultivares devem ser avaliados em dois ou mais ambientes contrastantes (Ramalho et al., 1993). Rosse (1999) relata que a interação entre cultivares e ambientes é facilmente detectada através de uma tabela de dupla entrada, sendo possível a ocorrência de três situações: ausência de interação, interação simples e interação complexa. As duas primeiras não causam problemas para a seleção e a recomendação de cultivares aos agricultores, pois não altera a classificação dos cultivares nos vários ambientes; porém, a terceira, por alterar o ordenamento dos cultivares frente aos ambientes avaliados, dificulta sensivelmente essa seleção e recomendação.

Segundo Ramalho et al., (1993), considerando um número maior de ambientes e de cultivares, a presença de interação complexa quase sempre indica a existência de cultivares especificamente adaptados a ambientes particulares. Isso impede que a recomendação de cultivares possa ser feita de maneira generalizada, sendo necessárias medidas que controlem ou minimizem os efeitos da interação para proceder recomendações mais seguras. A ocorrência de interação complexa entre os cultivares irá diminuir a eficiência dos programas de melhoramento, porque a seleção é realizada na média dos vários ambientes, o que não garante a seleção dos melhores cultivares para cada ambiente particular. 
O processo tradicional de investigar as interações entre cultivares e ambientes é a análise conjunta da variância, envolvendo vários experimentos.

Através desta análise, as magnitudes das interações são avaliadas pelos quadrados médios da interação cultivares $x$ locais, cultivares $x$ anos, cultivares $\mathrm{x}$ locais $\mathrm{x}$ anos e outros, conforme o propósito do melhorista. Porém, o fato de a interação cultivar $\mathrm{x}$ ambiente se mostrar significativa não diz muito, havendo a necessidade de subdividi-la para saber o que ela contém. Dessa forma, a variância da interação pode ser dividida em duas partes. A primeira parte é uma função da diferença na variabilidade genética dentro dos ambientes e corresponde à interação simples. A segunda parte aparece devido à falta de correlação genética entre os cultivares nos ambientes, correspondendo à interação complexa, e indica que o cultivar superior num ambiente pode não o ser em outro. Quando há predominância da parte complexa da interação, o trabalho do melhorista fica mais complexo (Vencovsky \& Barriga, 1992).

Existem pelo menos três meios de amenizar o efeito da interação: a) identificar os cultivares específicos para cada ambiente; b) realizar o zoneamento ecológico; c) identificar cultivares com maior estabilidade fenotípica. Desses três meios, a identificação de cultivares com maior estabilidade têm sido a mais utilizada. Existe na literatura uma série de revisões comparando o emprego de diversas metodologias empregadas na avaliação de estabilidade (Oliveira, 1976; Langer et al., 1979; Becker, 1981; Lin et al., 1986; Veronesi, 1995).

O zoneamento ecológico consiste na subdivisão de uma área heterogênea em sub-regiões mais uniformes, de modo que dentro de uma sub- 
região os cultivares não mostrem uma interação significativa com os ambientes (Duarte, 1988).

A identificação de cultivares específicos para cada lugar procura explorar de maneira vantajosa a interação cultivar com ambiente, com a intenção de maximizar ou capitalizar os ganhos genéticos dos materiais em um ambiente específico. Apesar de possível, sua aplicação é quase inexeqüível. O maior inconveniente é o alto custo da sua implementação (Ramalho et al., 1993).

As análises de adaptabilidade e estabilidade, para a identificação de cultivares de comportamento previsível e que sejam responsivos às variações ambientais, são os meios mais utilizados para amenizar as conseqüências da interação entre cultivar e ambiente e de obter informações para fazer a recomendação de cultivares com maior critério (Ramalho et al., 1993).

Cruz \& Regazzii (2001) afirmam que apesar dos estudos da interação entre cultivares e ambientes ser importante, não permite obter informações sobre o comportamento dos cultivares frente às variações ambientais. Por isso, a identificação de cultivares com maior estabilidade fenotípica são a alternativa mais amplamente empregada e aplicada (Ramalho et al., 1993).

\subsection{Estabilidade e adaptabilidade de cultivares}

\subsubsection{Conceitos básicos}

$\mathrm{Na}$ literatura existem diferentes definições sobre adaptabilidade de plantas cultivadas. Mariotti et al., (1976) citado por Santos (1980), consideram 
adaptabilidade como a capacidade de os cultivares aproveitarem, vantajosamente, o estímulo ambiental, e estabilidade como a capacidade de os cultivares apresentarem comportamento previsível em função do estímulo ambiental.

Morais (1980) associou essa definição de estabilidade como estabilidade de comportamento, a qual define uma característica varietal e que não deve ser confundida com estabilidade fenotípica, que segundo vários autores (Allard \& Bradshaw, 1964; Clay \& Allard, 1969; Eberhart \& Russell, 1966; Finlay \& Wilkinson, 1963; Jowett, 1972; Marshal \& Brown, 1973; Tai, 1971) refere-se à capacidade de os cultivares apresentarem pequenas variações no seu comportamento geral, quando submetidos a diferentes ambientes.

Para Finlay \& Wilkinson (1963) estabilidade média caracteriza um cultivar cuja produção varia diretamente de acordo com a capacidade dos ambientes em proporcionar altas ou baixas produtividades.

Verma et al., (1978) definiram o cultivar ideal como aquele que apresenta alta capacidade de produção associada à alta estabilidade em ambientes desfavoráveis e capacidade de resposta à melhoria das condições de ambiente. A estabilidade de comportamento de um cultivar também pode ser definida como a previsibilidade de sua adaptabilidade, ou em termos estatísticos, como o ajuste do cultivar ao modelo (linear, bissegmentado ou não-linear) adotado.

Becker (1981) caracterizou a estabilidade em dois tipos: estabilidade biológica ou homeostática e estabilidade agronômica. A estabilidade no sentido biológico é aquela que o cultivar mantém uma produtividade constante entre ambientes. A estabilidade agronômica é aquela em que o cultivar é considerado 
estável se produzir bem em relação ao potencial produtivo dos ambientes testados. Ocorre nas situações em que o cultivar mostra interação mínima com o ambiente, ou seja, aquele com rendimento previsível.

Lin et al., (1986) propuseram três conceitos de estabilidade fenotípica em função dos diversos parâmetros de avaliação: estabilidade do tipo 1, tipo 2 e tipo 3, detalhadas a seguir:

Tipo 1: o cultivar é considerado estável se sua variância ambiental for baixa (conceito biológico de Becker, 1981). Pode ser mensurada a partir da estimativa da variância de cada cultivar nos diferentes ambientes. Esse tipo de estabilidade não é desejável agronomicamente, pois mostra uma tendência de associação entre as menores estimativas das variâncias estarem associadas às baixas médias.

Tipo 2: o cultivar estável é aquele cuja resposta aos ambientes aproxima-se da resposta média de todos os cultivares dos experimentos (conceito agronômico de Becker, 1981). Esse tipo de estabilidade acompanha o desempenho médio dos cultivares frente às variações ambientais, permitindo identificar materiais estáveis e com potencial para se manter entre os melhores nos ambientes. Lin et al., (1986) esclarecem que esse tipo de estabilidade é uma medida restrita aos materiais que estão sendo avaliados.

Tipo 3: o cultivar será estável se o quadrado médio do desvio da regressão for baixo, próximo a zero. Esse tipo de estabilidade é mensurado pelas metodologias que utilizam a análise de regressão.

Dentro dos conceitos propostos por Lin et al., (1986), o coeficiente de regressão proposto pela metodologia de Finlay \& Wilkinson (1963) pode 
corresponder ao conceito do tipo 1, se o cultivar estável for definido como aquele em que o coeficiente de regressão linear for $b_{i}=0$; no entanto, se o cultivar estável for definido como coeficiente de regressão for $b_{i}=1$, corresponderá ao conceito tipo 2 .

Rosse (1999) comenta que os parâmetros que determinam a estabilidade são específicos para os grupos de cultivares testados, bem como para os ambientes considerados, sendo errôneo extrapolar os resultados para outras condições. Pelo trabalho de Vencovsky \& Torres (1988), a correlação entre a estabilidade temporal e estabilidade geográfica (entre locais) foi não significativa em milho, indicando que ambas apresentam controle genético independente.

Rosse (1999) relata que vários estudos têm mostrado que a estabilidade é um caráter que apresentam herdabilidade inferior à herdabilidade do caráter produtividade (Bonato, 1978; Santos, 1980; Torres, 1988; Davide, 1992; Farias et al., 1998) não havendo nenhum resultado conclusivo com relação ao número de locos que a controlam; mas acredita-se que seja um número razoavelmente grande e de herança complexa, o que dificulta a sua seleção para fins de melhoramento.

\subsubsection{Principais metodologias}

São muitas as metodologias de análise de adaptabilidade e estabilidade destinada a um grupo de cultivares testados em vários ambientes. A diferença 
entre eles origina-se nos próprios conceitos de estabilidade e nos procedimentos biométricos de medir a interação entre cultivares e ambientes (Vencosky \& Barriga, 1992). Existem métodos baseados em: variância da interação cultivares x ambientes; regressão linear; regressão linear bissegmentada; regressão não linear; métodos multivariados; métodos que integram métodos univariados e multivariados.

A escolha de um método de análise depende dos dados experimentais, principalmente relacionados com o número de ambientes disponíveis (Cruz \& Regazzi, 2001).

Essas metodologias deverão ser empregadas quando ocorrerem interações entre cultivares e ambientes significativas, sendo complementares às análises de variâncias individuais e conjuntas de dados experimentais realizados em uma série de ambientes. Revisões sobre esses procedimentos são comuns na literatura (Oliveira, 1976; Langer et al., 1979; Becker, 1981; Lin et al., 1986; Duarte, 1988; Veronesi, 1995).

Bonato (1978) comenta que a metodologia mais antiga para avaliar a performance genotípica é a tradicional análise de grupos de experimentos baseada na variância da interação entre cultivares e ambientes. Neste método, a variação de ambientes dentro de cada cultivar é usada como estimador do parâmetro de estabilidade, de modo que o cultivar que apresentar menor quadrado médio para ambientes é o mais estável.

Plaisted \& Peterson (1959) avaliaram a magnitude da contribuição de cada cultivar na variância da interação entre cultivares e locais. Os autores consideraram que cada cultivar contribui com uma magnitude para a variância, 
e o que apresentar menor contribuição será considerado o mais estável. O método de ecovalência (Wricke \& Weber, 1986) segue o mesmo princípio, sendo ecovalência o parâmetro que mede a contribuição de cada cultivar para a variância da interação total cultivares x ambientes, os cultivares mais estáveis serão aqueles que apresentarem ecovalências menores.

Essas metodologias baseadas na variância da interação entre cultivar e ambientes não têm sido muito utilizadas, pois não fornecem as informações necessárias aos propósitos do melhoramento (Rosse, 1999), visto que seus conceitos enquadram-se na estabilidade de Tipo 1 (estabilidade no sentido biológico) de Lin et al., (1986). A desvantagem é que cultivares que apresentam as variâncias menores são em geral os menos produtivos (Cruz \& Regazzi, 2001). Entretanto, esses métodos deram a base para que outras metodologias fossem propostas, como aquelas baseadas na regressão linear.

Os primeiros pesquisadores a trabalharem considerando um índice ambiental e a regressão linear foram Finlay \& Wilkinson (1963), com cevada. Eles estimaram o índice ambiental como a média de produtividade de todos os cultivares em cada ambiente. Esse valor foi submetido à transformação logarítmica para aumentar a linearidade na regressão e proporcionar maior homogeneidade das variâncias residuais. Esse método permite o desdobramento das somas de quadrados da interação entre cultivares e ambientes em regressão linear e desvios da regressão. Os conceitos de estabilidade e adaptabilidade estão relacionados com os coeficientes de regressão linear e com a média do cultivar. 
O método de Eberhart \& Russell (1966) se assemelha ao modelo proposto por Finlay \& Wilkinson (1963) nos parâmetros estimados, porém difere no conceito de estabilidade adotada, além de não requerer a transformação dos dados. O índice ambiental adotado foi diferente, sendo calculado pela diferença entre a média de todos os cultivares em um dado ambiente e a média geral.

Além do coeficiente de regressão linear $\left(b_{i}\right)$ e da produtividade média $\left(\bar{Y}_{i}\right)$, o quadrado médio dos desvios da regressão $\left(s_{d i}^{2}\right)$ é utilizado como parâmetro de estabilidade, e indica o grau de confiabilidade da resposta linear estimada, ou seja, a resposta à melhoria do ambiente. Assim um valor baixo de $s_{d i}^{2}$ significa dizer que o cultivar terá um comportamento semelhante se plantado em condições semelhantes. Se o cultivar apresentar um valor alto para esse parâmetro, dificilmente ele repetirá seu desempenho em ambientes parecidos.

Pinthus (1973) acrescentou à metodologia de Eberhart \& Russell (1966), a utilização do coeficiente de determinação $\left(R^{2}\right)$ como medida de estabilidade, em substituição do quadrado médio dos desvios da regressão $\left(s_{d i}^{2}\right)$, ou como auxílio, fornecendo uma medida da variação explicada pela regressão.

Os métodos de regressão linear simples para avaliar estabilidade fenotípica em plantas, têm sido muito discutidos e submetidos à algumas críticas de âmbito estatístico e biológico (Silva, 1995; Lin et al., 1986; Freeman \& Perkins, 1971; Crossa 1990).

Segundo Silva (1995), as variáveis preditoras da regressão linear são funções dos índices ambientais. Em conseqüência, os coeficientes de 
regressão são tendenciosos mostrando que a avaliação da performance genotípica é relativa ao grupo de cultivares avaliados.

Para Lin et al., (1986), o modelo de regressão para a interação entre cultivares e ambientes é descritivo, baseado nos dados que estão sendo avaliados, e não em um modelo de predição. Para um modelo de predição as variáveis deveriam ser quantificadas antes do experimento e o quadrado médio dos desvios teria propriedade determinística, que poderia ser associada com os cultivares.

A correlação entre os índices ambientais e os rendimentos de cada cultivar, infringe suposições estatísticas da análise de regressão, podendo levar a regressões inválidas (Freeman \& Perkins, 1971). Isso viola o princípio básico da análise da regressão que é a independência entre as variáveis dependentes e independentes. A independência pode ser um problema quando o número de cultivares é pequeno $(<15)$. Numa situação assim, cada cultivar pode ter uma grande influência sobre a estimativa do índice ambiental, caracterizando a não independência (Crossa, 1990).

Há uma limitação quando poucos locais com desempenhos discrepantes são incluídos na análise de regressão linear simples. A adaptação de um dado cultivar pode ser devida à sua performance naquele ambiente extremo, podendo mascarar os resultados. Esse autor acrescenta que as estimativas obtidas não podem ser extrapoladas, mas que os resultados obtidos são relativos aos cultivares e aos ambientes envolvidos. Pode ocorrer de a classificação de dois cultivares com relação ao coeficiente de estabilidade ser 
completamente diferente quando eles forem comparados com outros dois grupos diferentes (Crossa, 1990).

Verma et al., (1978) propuseram um método de regressão que consiste na regressão linear bissegmentada. Essa proposta surgiu da incapacidade das análises convencionais em identificar cultivares teoricamente ideais, que seriam aqueles com sensibilidades relativamente baixas em ambientes pobres, mas sensíveis a ambientes favoráveis. Para isso recomendaram o ajustamento de duas retas, correspondendo à subdivisão dos ambientes em favoráveis e desfavoráveis, calculados como propuseram Eberhart \& Russell (1966).

De acordo com este método uma reta de regressão mede a sensibilidade dos cultivares em ambientes favoráveis, cujos índices são positivos, e a outra reta os desfavoráveis, cujos índices são negativos. Portanto, são estimados dois coeficientes de regressão separadamente, o coeficiente $b_{1}$, que determina a resposta de um cultivar aos ambientes desfavoráveis, e o coeficiente $b_{2}$, que determina a resposta aos ambientes favoráveis.

Essa metodologia foi modificada por Silva \& Barreto (1985) que propuseram o uso de um modelo de regressão múltipla que permite o ajustamento, para cada cultivar, de uma curva única constituída de dois segmentos de reta conectados no ponto correspondente ao índice ambiental nulo (Vencovsky \& Barriga, 1992). Porém, a metodologia não apresentava testes de hipótese consistentes para os parâmetros e exigia algumas alterações estatísticas para eliminar a correlação residual entre as estimativas ( $b_{1}$ e $\left.b_{1}+b_{2}\right)$ e as médias. 
Posteriormente, Cruz et al., (1989) propuseram alterações para facilitar a precisão das estimativas. Nas modificações proposta pelos autores as estimativas $b_{1}$ e $b_{1}+b_{2}$ não são correlacionadas entre si, pois as duas linhas de regressão não se tocam necessariamente no ponto onde o índice ambiental é nulo, o que levou à independência dos dois segmentos da reta.

Vencovsky \& Barriga (1992) comentam, em relação à escolha do método, que o método de Eberhart \& Russell deve ser empregado quando se dispõe de um número de ambientes de três a sete, a grosso modo, indicando que para um pequeno número de ambientes este método é o único viável. Quando o número de ambientes for igual ou maior do que oito, pode-se adotar o modelo bissegmetnado.

As técnicas multivariadas têm sido aplicadas para o estudo sob este enfoque. Essas técnicas são mais complexas estatisticamente, porém os resultados permitem interpretações mais coerentes com a realidade biológica (Rosse, 1999) permitindo explorar melhor os dados.

A análise multivariada permite eliminar os ruídos presentes nos dados, sumarizar e relevar a estrutura dos dados para elucidar a estrutura interna destes a partir de hipóteses que podem ser geradas e depois testados por métodos estatísticos (Crossa, 1990). Uma das metodologias que vem ganhando uso é a análise AMMI, que representa um modelo linear de efeitos aditivos de cultivares e ambientes e, bi-linear de efeito multiplicativo para a interação cultivares $\mathrm{x}$ ambiente. Esta metodologia permite um detalhamento maior da soma de quadrados da interação (Zobel et al., 1988), sendo uma vantagem na 
seleção de cultivares, quando comparado com outros métodos. Porém, sua desvantagem é a não apresentação de um padrão de resposta dos cultivares e dificuldade na interpretação (Crossa, 1990).

Lin \& Binns (1988) propuseram uma metodologia para identificar os cultivares estáveis entre os melhores que apresentem desempenho próximo ao máximo obtido, e que consigam manter-se em maior gama de ambientes, denominada de $P_{i}$. Este parâmetro é uma medida de superioridade máxima de um cultivar, que representa o quadrado médio da distância entre a resposta do cultivar e resposta do cultivar que apresenta produtividade máxima, entre todos os cultivares de um determinado ambiente. Quanto menor esse parâmetro, mais estável será o cultivar.

Metodologias baseadas em análise de regressão não-linear também têm sido propostas, dentre as quais se destaca a metodologia apresentada por Toler (1990). O grupo de cultivares avaliados é classificado em cinco diferentes grupos de acordo com o seu padrão resposta, representando um aprimoramento da análise de estabilidade e adaptabilidade que utilizam unicamente a regressão linear.

\subsubsection{Estudos de estabilidade no algodoeiro}

A aplicação desses métodos de estabilidade e adaptabilidade vem sendo utilizada em diversas culturas, antes da sua recomendação aos agricultores 
(Bonato, 1978; Torres, 1988; Davide, 1992; Soares, 1992; Freire et al., 1994, Farias, 1995; Veronesi, 1995; Rosse, 1999; Rocha, 2002).

Estudos no Brasil sobre a estabilidade e adaptabilidade fenotípica de cultivares para o caráter produtividade do algodão em caroço foram realizados por alguns autores (Moreira et al., 1983; Santana, et al., 1983; Freire et al., 1994; Carvalho et al., 1995; Farias, 1995; Machado et al., 2001; Sobreira et al., 2003).

Santana et al., (1983) avaliou a estabilidade e adaptabilidade na produção de nove cultivares de algodoeiro herbáceo, obtidos do Ensaio Nacional de cultivares conduzido em estados do Nordeste e Minas Gerais nos anos de 1977/78 e 1978/79, utilizando a metodologia de Eberhart \& Russell. Destacaram-se quanto à estabilidade e adaptabilidade os cultivares BR-1, IAC18, SL 7-1 e IAC 12-2RB.

Farias (1995) realizou uma pesquisa que compreendeu dados de produção provenientes de 75 experimentos de avaliação de cultivares do algodão da região Nordeste, no período que se estende de 1981 a 1992. Nas avaliações foram estimados os parâmetros de estabilidade e adaptabilidade usando as metodologias propostas por Eberhart \& Russell (1966), Cruz et al., (1989) e Lin \& Binns (1988). O autor observou que a cultivar CNPA Giorge-I foi o mais instável e menos adaptada, enquanto CNPA 6H e IAC 20 foram as mais adaptadas e estáveis.

Machado et al., (2001) utilizando dados de produção de algodão em caroço e porcentagem de fibra, coletados do Ensaio Regional de linhagens e cultivares da EPAMIG, no Estado de Minas Gerais, estimou os parâmetros de 
estabilidade e adaptabilidade através de três metodologias: Eberhart \& Russel (1966), Lin \& Binns (1988) e Annicchiarico (1992). Destacaram-se nas análises para o caráter produtividade as linhagens MG 863192, MG 863579, MG 864133 e MG 863210.

Sobreira et al., (2003), avaliou a estabilidade e adaptabilidade de cultivares para o caráter produção de algodão em caroço $(\mathrm{kg} / \mathrm{ha})$. Foram utilizados dados provenientes do Ensaio Final de avaliação da EmbrapaAlgodão no Estado do Mato Grosso de oito cultivares conduzidos em 12 localidades, utilizando a metodologia proposta por Eberhart \& Russell (1966). Conclui-se que todos os cultivares avaliados apresentaram estabilidade geral ou ampla, porém nem todos foram considerados de comportamento previsível. Os cultivares que se destacaram foram: ITA-90, MT 96-212 e CNPA 96-124, com produtividade elevada, adaptabilidade ampla $\left(b_{i}=1\right)$ e comportamento previsível, reunindo características favoráveis e sendo recomendados para o cultivo no Estado do Mato Grosso. 


\section{MATERIAL E MÉTODOS}

\subsection{Características dos experimentos}

Foram utilizados dados obtidos do Ensaio Nacional de cultivares de algodoeiro herbáceo conduzidos pela Embrapa-Algodão durante o triênio 1998/99, 1999/00 e 2000/01, no Estado do Mato Grosso avaliados em 14, 17 e 15 locais, respectivamente. Na Tabela 1 encontra-se a relação dos municípios e respectivas coordenadas geográficas, onde os experimentos foram avaliados. Os cultivares avaliados, suas origens e os anos agrícolas em que foram utilizados estão apresentados na Tabela 2.

Os experimentos foram conduzidos em dois sistemas de produção: familiar e empresarial.

O sistema familiar caracteriza-se pelo cultivo de pequenas áreas. Localizase em regiões de condições naturais favoráveis à cultura, em vales férteis, com uso intensivo de mão-de-obra familiar do plantio à colheita. Cada produtor cultiva em média cinco hectares e a produtividade média situa-se em 1.800 kg/ha (Anuário Brasileiro do Algodão, 2001). Utilizam pouca quantidade de fertilizantes e corretivos, baixa população de plantas por área, controle 
Tabela 1. Coordenadas geográficas dos municípios onde foram conduzidos os experimentos do Ensaio Nacional de algodoeiro herbáceo no Estado do Mato Grosso, nos anos agrícolas 1998/99 ${ }^{(1)}, 1999 / 00^{(2)}$ e $2000 / 01^{(3)}$

\begin{tabular}{|c|c|c|c|}
\hline Municípios & Anos & Latitude (S) & Longitude (W) \\
\hline Alto Taquari & 1,2 & 17049'34" S & $53^{\circ} 16^{\prime} 56^{\prime \prime} \mathrm{W}$ \\
\hline Cáceres & $1,2,3$ & $16^{\circ} 04^{\prime} 14^{\prime \prime} \mathrm{S}$ & $57^{\circ} 40^{\prime} 44^{\prime \prime} \mathrm{W}$ \\
\hline Campo Novo do Parecis* & $1,2,3$ & $13^{\circ} 40^{\prime} 31^{\prime \prime} \mathrm{S}$ & 57053'31"W \\
\hline Campo Verde & $1,2,3$ & $15^{\circ} 32^{\prime} 48^{\prime \prime} \mathrm{S}$ & $55^{\circ} 10^{\prime} 08^{\prime \prime} \mathrm{W}$ \\
\hline Colíder & 3 & $10^{\circ} 49^{\prime} 04^{\prime \prime} \mathrm{S}$ & $55^{\circ} 27^{\prime} 03^{\prime \prime} \mathrm{W}$ \\
\hline Glória D'Oeste & 2 & $15^{\circ} 46^{\prime} 06^{\prime \prime} \mathrm{S}$ & 58013'04" W \\
\hline Itiquira & 2 & $17^{\circ} 12 ' 32 " \mathrm{~S}$ & $54^{\circ} 09^{\prime} 01^{\prime \prime} \mathrm{W}$ \\
\hline Lucas do Rio Verde & $1,2,3$ & $13^{\circ} 03^{\prime} 01^{\prime \prime} \mathrm{S}$ & $55^{\circ} 54^{\prime} 40^{\prime \prime} \mathrm{W}$ \\
\hline Nova Mutum & 1,2 & $13^{\circ} 49^{\prime} 44^{\prime \prime} \mathrm{S}$ & $56^{\circ} 04^{\prime} 56^{\prime \prime} \mathrm{W}$ \\
\hline Novo São Joaquim & 3 & $14^{\circ} 54^{\prime} 21^{\prime \prime} \mathrm{S}$ & $53^{\circ} 01^{\prime} 06^{\prime \prime} \mathrm{W}$ \\
\hline Pedra Preta & $1,2,3$ & 16037'23" S & $54^{\circ} 28^{\prime} 26^{\prime \prime} \mathrm{W}$ \\
\hline Pontes e Lacerda & $1,2,3$ & $15^{\circ} 13^{\prime} 34^{\prime \prime} \mathrm{S}$ & 59020'07" W \\
\hline Primavera do Leste & $1,2,3$ & 15033'32" S & $54^{\circ} 17^{\prime} 46^{\prime \prime} \mathrm{W}$ \\
\hline Rondonópolis & $1,2,3$ & $16^{\circ} 28^{\prime} 15^{\prime \prime} \mathrm{S}$ & $54^{\circ} 38^{\prime} 08^{\prime \prime} \mathrm{W}$ \\
\hline São José dos Quatro Marcos & $1,2,3$ & 15037'17"S & 58010'35" W \\
\hline Sapezal & $1,2,3$ & $12^{\circ} 59^{\prime} 22^{\prime \prime S}$ & $58^{\circ} 45^{\prime} 51^{\prime \prime} \mathrm{W}$ \\
\hline Sinop & $1,2,3$ & 11051'51"S & 55030'09" W \\
\hline Sorriso & 2,3 & $12^{\circ} 32^{\prime} 43^{\prime \prime S}$ & $57^{\circ} 29^{\prime} 09^{\prime \prime} \mathrm{W}$ \\
\hline Tangará da Serra & 1,3 & 14'37'10"S & 57029'09" W \\
\hline
\end{tabular}

* No ano agrícola 1999/00 foram conduzidos dois experimentos em Campo Novo do Parecis.

inadequado de pragas, e os cultivares utilizados não são adaptados às condições do ambiente, principalmente quanto à resistência a ramulose, doença de grande importância regional (Carvalho \& Chiavegato, 1999). 
Tabela 2. Cultivares utilizados nos experimentos do Ensaio Nacional de algodoeiro herbáceo e suas origens, nos anos agrícolas de $1998 / 99^{(1)}, 1999 / 00^{(2)}$ e $2000 / 01^{(3)}$

\begin{tabular}{lll}
\hline Cultivares & \multicolumn{1}{c}{ Origem } & \multicolumn{1}{c}{ Anos avaliados $^{(1,2,3)}$} \\
\hline COODETEC 404 & COODETEC & 1 e 2 \\
IAC 96-280 & IAC & 1 \\
CNPA-7H & Embrapa Algodão & 1 \\
ANTARES & Embrapa Algodão & 1 \\
DELTA OPAL & Delta Pine & 1,2 e 3 \\
EPAMIG PREC-1 & Embrapa Algodão & 1 \\
IAC 96-319 & IAC & 1 e 2 \\
DELTAPINE 4025 & Delta Pine & 1 \\
ITA-96 & Embrapa Algodão & 1 \\
DELTAPINE 4049 & Delta Pine & 1 e 3 \\
FMT-SATURNO & Fundação MT & 2,3 \\
BRS 743 & Embrapa Algodão & 2 \\
IAPAR 96-1734 & IAPAR & 2 \\
IAC 97-86 & IAC & 2 \\
COODETEC 402 & COODETEC & 1 e 2 \\
CNPA 8733 & Embrapa Algodão & 2 \\
IAPAR 97-141 & IAPAR & 2 \\
IAC 96-319 & IAC & 2 \\
EPAMIG ALVA & EPAMIG & 2 \\
ITA-90 & Embrapa Algodão & 1,2 e 3 \\
BRS 97-1682 & Embrapa Algodão & 3 \\
BRS 201 & Embrapa Algodão & 3 \\
BRS CEDRO & Embrapa Algodão & 3 \\
IPR 94 & IAPAR & 3 \\
IPR 96 & IAPAR & 3 \\
IAC 97-86 & IAC & 3 \\
CNPA/96-1202 & Embrapa Algodão & 3 \\
EPAMIG LIÇA & EPAMIG & 3 \\
\hline & & \\
\hline
\end{tabular}

Já o sistema empresarial caracteriza-se pelo: cultivo de grandes áreas (100 a 5.000 hectares), uso de sementes de boa qualidade, uso de herbicidas, 
reguladores de crescimento e desfolhantes, correção de solo através de calagem e adubação química com macro e micronutrientes, mecanização total de todas as operações, não realização de desbaste, controle de pragas e doenças de importância econômica, colheita mecanizada, pós-colheita com destruição dos restos culturais, rotação de culturas, transporte do algodão em gaiolas e beneficiamento em descaroçadoras, com comercialização da pluma e sementes (EMPAER, 1992; EMPAER, 1997; FUNDAÇÃO MT, 1996). Segundo Melo Filho (2003) a produtividade em tais áreas é superior a $3.361 \mathrm{~kg} / \mathrm{ha}$.

Os experimentos foram conduzidos em delineamentos em blocos casualizados, com quatro repetições. A parcela experimental foi constituída de quatro fileiras de cinco metros, com espaçamento de 0,75 a 1,0 m entre fileiras e dez plantas por metro. A distância entre blocos foi de três metros. Após o desbaste. Foram colocadas bordaduras com duas fileiras do cultivar ITA-90 no início e fim de cada bloco. A área útil da parcela foi constituída pelas duas fileiras centrais. Cada experimento ocupou uma área de 2.340,00 $\mathrm{m}^{2}$.

O plantio de cada experimento foi feito na época apropriada às condições climáticas do Estado do Mato Grosso, que compreende os meses de novembro, dezembro e janeiro. Aos 20-30 dias após a emergência das plantas, foi feito desbaste deixando-se sete plantas/metro linear. Colocou-se N, P e K na base e $\mathrm{N}, \mathrm{K}$ e Boro em cobertura, entre 25 e 35 dias após a emergência. As práticas culturais seguiram as condições de manejo adotadas por cada sistema: empresarial ou familiar, utilizadas pelos produtores do município (Tabela 3). 
Tabela 3. Municípios, sistema de produção e números de experimentos do Ensaio Nacional de algodoeiro herbáceo no Estado do Mato Grosso, nos anos agrícolas 1998/99, 1999/00 e 2000/01

\begin{tabular}{|c|c|c|c|c|c|}
\hline \multirow{2}{*}{ Municípios } & \multirow{2}{*}{$\begin{array}{l}\text { Sistema de } \\
\text { produção }\end{array}$} & \multicolumn{4}{|c|}{ Números de experimentos } \\
\hline & & $1998 / 99$ & $1999 / 00$ & $2000 / 01$ & Total \\
\hline Alto Taquari & Empresarial & 1 & 1 & - & 2 \\
\hline Cáceres & Familiar & 1 & 1 & 1 & 3 \\
\hline Campo Novo do Parecis & Empresarial & 1 & 2 & 1 & 4 \\
\hline Campo Verde & Empresarial & 1 & 1 & 1 & 3 \\
\hline Colíder & Familiar & - & - & 1 & 1 \\
\hline Glória D’Oeste & Familiar & - & 1 & - & 1 \\
\hline Itiquira & Empresarial & - & 1 & - & 1 \\
\hline Lucas do Rio Verde & Empresarial & 1 & 1 & 1 & 3 \\
\hline Nova Mutum & Empresarial & 1 & 1 & - & 2 \\
\hline Novo São Joaquim & Empresarial & - & - & 1 & 1 \\
\hline Pedra Preta & Empresarial & 1 & 1 & 1 & 3 \\
\hline Pontes e Lacerda & Familiar & 1 & 1 & 1 & 3 \\
\hline Primavera do Leste & Empresarial & 1 & 1 & 1 & 3 \\
\hline Rondonópolis & Empresarial & 1 & 1 & 1 & 3 \\
\hline São José dos Quatro Marcos & Familiar & 1 & 1 & 1 & 3 \\
\hline Sapezal & Empresarial & 1 & 1 & 1 & 3 \\
\hline Sinop & Familiar & 1 & 1 & 1 & 3 \\
\hline Sorriso & Empresarial & - & 1 & 1 & 2 \\
\hline Tangará da Serra & Familiar & 1 & - & 1 & 2 \\
\hline Total & & 14 & 17 & 15 & 46 \\
\hline
\end{tabular}

O controle de doenças não foi realizado; porém, utilizaram-se inseticidas, herbicidas, redutores de crescimento e desfolhantes.

Foram feitas duas colheitas, sendo a primeira quando 50 a $70 \%$ dos capulhos estavam abertos e a segunda 15 a 30 dias depois. Os dados que foram utilizados para análise referem-se à produção total de algodão em caroço $(\mathrm{kg} / \mathrm{ha})$ das duas colheitas. 


\subsection{Análises estatísticas}

\subsubsection{Análises de variância}

Inicialmente foi feita a análise de variância de cada experimento, considerando-se fixo o efeito de tratamentos (cultivares), de acordo com o seguinte modelo matemático:

$$
Y_{i j}=m_{i}+t_{i}+b_{j}+e_{i j}
$$

em que:

$Y_{i j}$ : valor do tratamento i no bloco j;

$m_{i}:$ média geral;

$t_{i}$ : efeito do tratamento $\mathrm{i} ; \mathrm{i}=1,2, \ldots \mathrm{I}$;

$b_{j}$ : efeito do bloco $\mathrm{j} ; \mathrm{j}=1,2, \ldots \mathrm{J}$;

$e_{i j}$ : erro experimental associado à parcela ij.

Em seguida realizou-se uma análise de variância conjunta para cada sistema (empresarial ou familiar) por ano, tendo como objetivo verificar a presença da interação entre tratamentos e locais. Foi considerado fixo o efeito de tratamentos (cultivares) e aleatório o de locais, de acordo com o seguinte modelo matemático:

$$
Y_{i j k}=m_{i}+t_{i}+l_{k}+(t l)_{i k}+b_{j(k)}+e_{i j k}
$$


em que:

$Y_{i j k}$ : valor do tratamento i, no bloco j, no local k;

$m_{i}:$ média geral;

$t_{i}$ : efeito do tratamento $\mathrm{i} ; \mathrm{i}=1,2, \ldots \mathrm{I}$;

$l_{k}$ : efeito do local $\mathrm{k} ; \mathrm{k}=1,2, \ldots \mathrm{K}$;

$(t l)_{i k}$ : efeito interação do cultivar i com o local k;

$b_{j(k)}:$ efeito do bloco j dentro do local $k ; j=1,2, \ldots \mathrm{J}$;

$e_{i j k}:$ erro experimental associado à parcela ijk.

O esquema da análise de variância, de acordo com este modelo, encontrase na Tabela 4.

Tabela 4. Esquema da análise de variância com respectivas esperanças do quadrado médio, utilizada na análise conjunta

\begin{tabular}{lcclc}
\hline FV & GL & QM & E(QM) & F \\
\hline Blocos/Locais & $\mathrm{K}(\mathrm{J}-1)$ & $Q_{1}$ & $\sigma^{2}+I \sigma_{B}^{2}$ & $Q_{1} / Q_{5}$ \\
Locais (L) & $(\mathrm{K}-1)$ & $Q_{2}$ & $\sigma^{2}+I \sigma_{B}^{2}+I J \sigma_{L}^{2}$ & $Q_{2} / Q_{1}$ \\
Tratamentos (T) & $(\mathrm{I}-1)$ & $Q_{3}$ & $\sigma^{2}+J \frac{I}{I-1}+J K \frac{\sum_{i} I_{i}^{2}}{I-1}$ & $Q_{3} / Q_{4}$ \\
Tx L & $(\mathrm{I}-1)(\mathrm{K}-1)$ & $Q_{4}$ & $\sigma^{2}+J \frac{I}{I-1} \sigma_{G L}^{2}$ & $Q_{4} / Q_{5}$ \\
Resíduo médio & $\mathrm{K}(\mathrm{I}-1)(\mathrm{J}-1)$ & $Q_{5}$ & $\sigma^{2}$ & \\
\hline
\end{tabular}

Todas as análises de variância foram realizadas utilizando o procedimento programa SAS (SAS INSTITUTE, 1999). 
Foi feito o desdobramento da interação, e os resultados foram transformados em porcentagem (\%), utilizando-se a seguinte expressão dada por Vencoksky \& Barriga (1992):

$$
\sigma_{T L}^{2}=(1 / 2) \sum_{i<i^{\prime}}^{1}\left[\left(\sigma_{T_{i}}-\sigma_{T_{i^{\prime}}}\right)^{2}+2\left(1-\rho_{i i^{\prime}}\right) \sigma_{T_{i}} \sigma_{T_{i^{\prime}}}\right]
$$

\subsubsection{Análise de adaptabilidade e estabilidade fenotípica}

Os parâmetros de estabilidade e adaptabilidade dos cultivares foram estimados utilizando-se as metodologias de regressão linear simples (Eberhart \& Russell,1966). As análises foram efetuadas através do programa GENES (Cruz, 2001).

Foram utilizados dados médios de cada local para cada sistema (empresarial ou familiar) em cada ano. Os parâmetros de estabilidade foram estimados utilizando o seguinte modelo matemático:

$$
\bar{Y}_{i k}=m_{i}+b_{i} I_{k}+s_{d_{i k}}^{2}+\bar{e}_{i k}
$$

em que:

$\bar{Y}_{i k}$ : média do tratamento i no local k;

$m_{i}:$ média geral do tratamento i;

$b_{i}$ : coeficiente de regressão linear, que mede a resposta dos cultivares à variação do local;

$I_{k}$ : índice ambiental para local sendo: 


$$
\begin{gathered}
I_{k}=\bar{Y}_{. k}-\bar{Y}_{. .}, \text {e } \sum_{\mathrm{k}=1}^{\mathrm{k}} \mathrm{I}_{\mathrm{k}}=0 \\
s_{d_{k k}}^{2}: \text { desvio de regressão do tratamento i no local k; } \\
\bar{e}_{i k}: \text { erro experimental médio. }
\end{gathered}
$$

Portanto, de acordo com este modelo, a adaptabilidade é avaliada pelo parâmetro $b_{i}$ e a estabilidade por $s_{d i}^{2}$. Para verificar o ajuste do modelo, calculase também o coeficiente de determinação $R^{2}$.

O esquema da análise de variância de acordo com este modelo encontra-se na Tabela 5.

Segundo esta metodologia, os cultivares mais adaptados são aqueles que apresentam uma média alta associado a uma estimativa de $b_{i}=1$. Quando $b_{i}>1$, os cultivares serão adaptados aos ambientes favoráveis (médias acima da média geral) e estão associados a alta resposta à melhoria ambiental. Quando $b_{i}<1$, os cultivares serão adaptados a ambientes desfavoráveis (médias abaixo da média geral), e estão associados à baixa resposta à melhoria ambiental.

A estabilidade é avaliada pelos desvios da regressão $\left(s_{d i}^{2}\right)$; quando $s_{d i}^{2}=$ 0 , a estabilidade ou previsibilidade é alta; quando $s_{d i}^{2} \neq 0$, os cultivares têm estabilidade baixa ou comportamento imprevisível.

Tabela 5. Esquema da análise de variância usado no estudo da estabilidade e adaptabilidade, conforme a metodologia de Eberhart \& Russell (1966) 


\begin{tabular}{lllcc}
\hline FV & $\mathrm{GL}$ & & $\mathrm{QM}$ & $\mathrm{F}$ \\
\hline Locais (L) & $\mathrm{K}-1$ & & $Q_{1}$ & $Q_{1} / Q_{8}$ \\
Tratamento (T) & $\mathrm{I}-1$ & & $Q_{2}$ & $Q_{2} / Q_{8}$ \\
T x L & $(\mathrm{I}-1)(\mathrm{K}-1)$ & & $Q_{3}$ & $Q_{3} / Q_{8}$ \\
$\mathrm{~L} / \mathrm{T}$ & $\mathrm{I}(\mathrm{K}-1)$ & & $Q_{4}$ & $Q_{4} / Q_{8}$ \\
L (linear) & & 1 & $Q_{5}$ & $Q_{5} / Q_{8}$ \\
T x L (linear) & & $\mathrm{I}-1$ & $Q_{6}$ & $Q_{6} / Q_{8}$ \\
Desvio combinado (L/T) & & $\mathrm{I}(\mathrm{K}-2)$ & $Q_{7}$ & $Q_{7} / Q_{8}$ \\
Desvio/T 1 & & $\mathrm{~K}-2$ & $Q_{G_{1}}$ & $Q_{G_{1}} / Q_{8}$ \\
N & & $\mathrm{N}$ & $\mathrm{N}$ & $\mathrm{N}$ \\
Desvio/T, & & $\mathrm{K}-2$ & $Q_{G_{I}}$ & $Q_{G_{I}} / Q_{8}$ \\
Resíduo & & & $Q_{8}$ & \\
\hline
\end{tabular}

O cultivar ideal, segundo os autores desta metodologia portanto, será aquele que apresentar média alta, adaptabilidade ampla $\left(b_{i}=1\right)$ e alta estabilidade ou previsibilidade $\left(s_{d i}^{2}=0\right)$. 


\section{RESULTADOS E DISCUSSÃO}

Das 19 localidades desta pesquisa, 11 foram incluídas nos três anos, quatro em dois anos e quatro foram incluídos em apenas um ano (Tabela 1). Dentre os 28 cultivares avaliados, apenas os cultivares DELTA OPAL e ITA-90 foram avaliados por três anos consecutivos (Tabela 2).

O pequeno número de cultivares comuns entre os anos, de acordo com Rosse (1999), deve-se em parte à dinâmica dos programas de melhoramento genético, onde, a cada ano, novos cultivares são liberados no mercado, e outros, devido ao seu baixo desempenho são excluídos dos experimentos de competição, sendo então substituídos. Além disso, a maioria dos experimentos não é conduzida apenas com a finalidade de estudar a estabilidade fenotípica, mas sim outros atributos dos materiais genéticos.

Arias (1996) observou que entre os anos agrícolas 1987/1988 e 1993/1994, apenas 54\% de todos os cultivares de milho foram avaliados por mais de dois anos no Estado do Mato Grosso do Sul.

Essa alta taxa de substituição de cultivares pode comprometer as estimativas dos parâmetros de estabilidade e adaptabilidade nos métodos baseados em regressão linear, que são os mais utilizados, pois pode afetar a independência do índice ambiental. 
Segundo Vencovsky \& Torres (1986) a avaliação de cultivares por vários anos permite o estudo da estabilidade temporal, que seria preferível e mais importante para os pequenos produtores. No entanto nessa pesquisa não foi possível estimar a estabilidade no sentido temporal. Os parâmetros aqui estimados referem-se à estabilidade no sentido geográfico, ou seja, diversos locais no mesmo ano agrícola.

\subsection{Análises de variância individuais}

Os resultados das análises de variância individuais dos dados para o caráter produtividade de algodão em caroço $(\mathrm{kg} / \mathrm{ha})$ para cada município e ano agrícola, estão apresentados nos Anexos A a G. Nesses anexos constam: médias, quadrados médios de tratamentos (com respectivas significâncias), quadrados médios de resíduos e coeficiente de variação experimental.

Verifica-se que o coeficiente de variação experimental (CV), que a precisão experimental variou de 6,04\% (Pedra Preta em 1999/00) a 29,31\% (Pontes e Lacerda em 1998/99). A estimativa do CV médio foi de 11,73\%, valor inferior ao obtido por Estafanel et al., (1987), ou seja, 14,60\% para o mesmo caráter. Em experimentos conduzidos na Região Nordeste, Farias (1995) obteve CV médio de 23,10\% e Vidal Neto (2003) estimou CV médio de 24\%, para o mesmo caráter. Tais resultados indicam que os experimentos desta pesquisa apresentaram uma precisão experimental satisfatória.

Quanto aos efeitos de tratamentos verifica-se que dos 46 experimentos avaliados nos três anos, 38 mostraram significância pelo teste $F$ na 
produtividade média de algodão em caroço, indicando a existência de comportamento diferenciado entre os cultivares na maioria dos casos.

Nota-se ainda que as produtividades médias dos experimentos no sistema empresarial foram bem diferentes entre si (Anexos $A$ a D). A maior produtividade média $(5.117,9 \mathrm{~kg} / \mathrm{ha})$ ocorreu em Primavera do Leste em 1998/99, e a menor foi em Sapezal em 2000/01. Nas condições de agricultura familiar (Anexos E a G), a menor produtividade média foi em Pontes e Lacerda no ano agrícola de 1998/99 (648,6 kg/ha). Em contrapartida, Cáceres, em 2000/01, foi o local mais produtivo, apresentando uma produtividade média elevada, em se tratando de agricultura familiar (4.231,3 kg/ha).

\subsection{Análises de variâncias conjuntas}

Observa-se que as produtividades médias gerais dos anos 1998/99, 1999/00 e 2000/01 para experimentos no sistema empresarial (Tabela 6), estão bem acima da média brasileira de produtividade do algodoeiro $(1.153,0 \mathrm{~kg} / \mathrm{ha}) \mathrm{e}$ da média do Estado do Mato Grosso (1.374,0 kg/ha). Tais resultados obtidos para a produtividade média nas condições do cerrado, caracterizado por um sistema que utiliza elevado uso de insumos, estão de acordo com a estimativa feita por Takizawa (2000) de 3.150,0 kg/ha de algodão em caroço. Por outro lado, para o sistema familiar a produtividade média variou de $1.868,1 \mathrm{~kg} / \mathrm{ha}$ a $2.764,4 \mathrm{~kg} / \mathrm{ha}$ e, portanto, inferior às do sistema empresarial, fato já esperado. 
Tabela 6. Resumos das análises de variância conjuntas para o caráter produtividade de algodão em caroço $(\mathrm{kg} / \mathrm{ha})$ obtido dos experimentos do Ensaio Nacional de cultivares de algodoeiro herbáceo no sistema empresarial no Estado do Mato Grosso, nos anos agrícolas 1998/99, 1999/00 e 2000/01

\begin{tabular}{|c|c|c|}
\hline FV & GL & QM \\
\hline \multicolumn{3}{|l|}{ Ano 1998/99 } \\
\hline Tratamentos ( $\mathrm{T})$ & 11 & $2.953 .190,10^{\star \star}$ \\
\hline Locais (L) & 8 & $28.750 .784,30^{* *}$ \\
\hline $\mathrm{T} \times \mathrm{L}$ & 88 & $822.060,50^{* *}$ \\
\hline Resíduo & 292 & $268.756,50$ \\
\hline Média & $3.950,73$ & \\
\hline CV(\%) & 13,07 & \\
\hline \multicolumn{3}{|l|}{ Ano 1999/00 } \\
\hline Tratamentos $(\mathrm{T})$ & 10 & $9.104 .653,90^{\star *}$ \\
\hline Locais (L) & 11 & $36.664 .102,90 * \star$ \\
\hline TXL & 110 & $537.930,50 * *$ \\
\hline Resíduo & 353 & $218.728,80$ \\
\hline Média & $4.937,85$ & \\
\hline CV(\%) & 9,45 & \\
\hline \multicolumn{3}{|l|}{ Ano $2000 / 01$} \\
\hline Tratamentos ( $\mathrm{T})$ & 11 & $6.389 .100,00$ ** \\
\hline Locais (L) & 8 & $93.174 .743,80^{\star \star}$ \\
\hline $\mathrm{T} \times \mathrm{L}$ & 88 & $1.086 .497,30^{\star \star}$ \\
\hline Resíduo & 267 & $233.621,00$ \\
\hline Média & $3.958,09$ & \\
\hline CV(\%) & 12,09 & \\
\hline
\end{tabular}


Os resultados das análises de variância conjuntas dos experimentos para os anos 1998/99, 1999/00 e 2000/01 são apresentadas nas Tabelas 6 e 7 . Observou-se elevada significância $(P \leq 0,01)$ para o efeito de locais, tratamentos e interação tratamentos x locais em todas as análises.

A significância dos efeitos de tratamentos e locais revela que existiu diferença no comportamento entre eles, sendo constituídos de um grupo heterogêneo, e a significância da interação tratamentos x locais foi um indicativo da falta de consistência no comportamento dos tratamentos nos diversos locais.

Para todas as análises o Quadrado Médio de locais foi maior que o Quadrado Médio de tratamentos, e este, por sua vez, maior que o Quadrado Médio da interação tratamentos x locais, com exceção da análise de variância para as condições de agricultura familiar em 1999/00 (Tabela 7). A magnitude do efeito de locais evidenciou que as condições edafoclimáticas foram os principais responsáveis pelo comportamento diferenciado dos cultivares em relação à produtividade.

As interações tratamentos $\mathrm{x}$ locais significativas mostram, portanto que há influência das variações ambientais previsíveis e imprevisíveis, como citado por Allard \& Bradshaw (1964), no desempenho diferencial dos cultivares.

O desdobramento da fonte de variação tratamentos $x$ locais nos componentes simples e complexo auxilia no entendimento desta interação. Observa-se na Tabela 8 que nos dois sistemas o componente preponderante da interação foi o componente complexo, que é resultante da baixa correlação entre os cultivares nos diferentes locais. Isso indica, portanto, a necessidade de 
Tabela 7. Resumos das análises de variância conjuntas para o caráter produtividade de algodão em caroço (kg/ha) obtido dos experimentos do Ensaio Nacional de cultivares de algodoeiro herbáceo no sistema de agricultura familiar no Mato Grosso, nos anos agrícolas 1998/99, 1999/00 e 2000/01

\begin{tabular}{|c|c|c|}
\hline FV & GL & QM \\
\hline \multicolumn{3}{|l|}{ Ano 1998/99 } \\
\hline Tratamentos (T) & 11 & $530.087,87^{\star \star}$ \\
\hline Locais (L) & 4 & $50.650 .057,13^{\star \star}$ \\
\hline $\mathrm{T} \times \mathrm{L}$ & 44 & $486.046,10^{\star *}$ \\
\hline Resíduo & 156 & $123.120,10$ \\
\hline Média & $2.359,08$ & \\
\hline $\mathrm{CV}(\%)$ & 14,93 & \\
\hline \multicolumn{3}{|l|}{ Ano $1999 / 00$} \\
\hline Tratamentos $(\mathrm{T})$ & 10 & $210.692,47^{\star \star}$ \\
\hline Locais (L) & 4 & $20.919 .131,81^{\star \star}$ \\
\hline $\mathrm{T} X \mathrm{~L}$ & 40 & $233.029,50 * \star$ \\
\hline Resíduo & 150 & $58.376,40$ \\
\hline Média & $1.868,11$ & \\
\hline $\mathrm{CV}(\%)$ & 12,93 & \\
\hline \multicolumn{3}{|l|}{ Ano 2000/01 } \\
\hline Tratamentos (T) & 11 & $1.036 .658,00^{\star *}$ \\
\hline Locais (L) & 5 & $32.064 .920,90^{\star \star}$ \\
\hline $\mathrm{TXL}$ & 55 & $235.838,70^{\star \star}$ \\
\hline Resíduo & 192 & $82.237,80$ \\
\hline Média & $2.764,45$ & \\
\hline CV(\%) & 10,49 & \\
\hline
\end{tabular}

cautela ao fazer a recomendação de cultivares, já que o melhor cultivar para um local não o será necessariamente para os demais, nos dois sistemas. Este fato, 
Tabela 8. Contribuição (\%) da parte simples e complexa no desdobramento da fonte de variação $T \times L$ das análises de variância conjunta para o caráter produtividade de algodão em caroço $(\mathrm{kg} / \mathrm{ha})$, obtido dos experimentos do Ensaio Nacional de algodoeiro herbáceo para agricultura empresarial e familiar no Estado do Mato Grosso, nos anos agrícolas 1998/99, 1999/00 e 2000/01

\begin{tabular}{lcccccccc}
\hline & \multicolumn{3}{c}{ Empresarial } & & \multicolumn{3}{c}{ Familiar } \\
\cline { 2 - 3 } \cline { 7 - 8 } & $1998 / 99$ & $1999 / 00$ & $2000 / 01$ & & $1998 / 99$ & & $1999 / 00$ & $2000 / 01$ \\
\hline Simples & 26,13 & 9,14 & 27,34 & & 34,23 & 19,89 & 28,53 \\
Complexa & 73,96 & 90,86 & 72,66 & & 65,77 & 80,11 & 71,47 \\
\hline
\end{tabular}

portanto, justifica um maior detalhamento do desempenho relativo dos cultivares através dos parâmetros de estabilidade e adaptabilidade (Vencovsky \& Barriga, 1992).

\subsection{Adaptabilidade e estabilidade}

Nas Tabelas 9 e 10 estão apresentadas as análises de variância de acordo com a metodologia de Eberhart \& Russell (1966). Nota-se que os efeitos da decomposição de locais dentro de tratamentos foram significativos para todos os casos (Locais linear, T x L linear e Desvio Combinado). Os efeitos de locais lineares significativos indicam que os locais acarretaram variações significativas nas médias dos cultivares. A significância da fonte para $T \times L$ linear indica que houve diferença estatística entre os coeficientes de regressão linear de cada cultivar e que grande parte da interação tratamentos $x$ locais pode ser explicada pela regressão linear entre cultivares e diversos locais. 
Tabela 9. Resumo das análises de variância conjuntas para o caráter produtividade de algodão em caroço $(\mathrm{kg} / \mathrm{ha})$, segundo metodologia de Eberhart \& Russell (1966) no sistema de agricultura empresarial no Estado do Mato Grosso, nos anos agrícolas 1998/99, 1999/00 e 2000/01

\begin{tabular}{|c|c|c|}
\hline FV & GL & QM \\
\hline \multicolumn{3}{|l|}{ Ano 1998/99 } \\
\hline Tratamentos $(T)$ & 11 & $2.953 .190,10^{\star \star}$ \\
\hline Locais (L) & 8 & $28.750 .784,30 * \star$ \\
\hline$T \times L$ & 88 & $822.060,50$ ** \\
\hline $\mathrm{L} / \mathrm{T}$ & 96 & $3.196 .842,56^{\star \star}$ \\
\hline Locais Linear & 1 & $232.563 .055,21^{\star *}$ \\
\hline $\mathrm{T} \times$ Locais Linear & 11 & $1.488 .410,26^{\star \star}$ \\
\hline Desvio Combinado & 84 & $69.0015,69 * *$ \\
\hline Resíduo & 292 & $268.756,50$ \\
\hline \multicolumn{3}{|l|}{ Ano 1999/00 } \\
\hline Tratamentos $(\mathrm{T})$ & 10 & $9.104 .653,90^{\star \star}$ \\
\hline Locais (L) & 11 & $36.664 .102,90^{\star \star}$ \\
\hline $\mathrm{T} \times \mathrm{L}$ & 110 & $537.930,50^{\star *}$ \\
\hline $\mathrm{L} / \mathrm{T}$ & 121 & $3.882 .382,39 * \star$ \\
\hline Locais Linear & 1 & $409.071 .376,99 * *$ \\
\hline $\mathrm{T} \times$ Locais Linear & 10 & $1.303 .247,39 * *$ \\
\hline Desvio Combinado & 110 & $433.312,89 * \star$ \\
\hline Resíduo & 353 & $218.728,80$ \\
\hline \multicolumn{3}{|l|}{ Ano 2000/01 } \\
\hline Tratamentos $(\mathrm{T})$ & 11 & $6.389 .100,00^{\star *}$ \\
\hline Locais (L) & 8 & $93.174 .743,80^{\star *}$ \\
\hline$T \times L$ & 88 & $1.086 .497,30^{\star \star}$ \\
\hline $\mathrm{L} / \mathrm{T}$ & 96 & $10.352 .528,14^{\star *}$ \\
\hline Locais Linear & 1 & $880.775 .838,17^{\text {** }}$ \\
\hline $\mathrm{T} \times$ Locais Linear & 11 & $4.576 .513,50$ ** \\
\hline Desvio Combinado & 84 & $746.728,75^{\star \star}$ \\
\hline Resíduo & 267 & $233.621,00$ \\
\hline
\end{tabular}


Tabela 10. Resumo das análises de variância conjuntas para o caráter produtividade de algodão em caroço (kg/ha), segundo metodologia de Eberhart \& Russell (1966) no sistema de agricultura familiar no Estado do Mato Grosso, nos anos agrícolas 1998/99, 1999/00 e 2000/01

\begin{tabular}{|c|c|c|}
\hline FV & GL & QM \\
\hline \multicolumn{3}{|l|}{ Ano 1998/99 } \\
\hline Tratamentos $(\mathrm{T})$ & 11 & $530.087,87^{\star \star}$ \\
\hline Locais (L) & 4 & $50.650 .057,13^{\star \star}$ \\
\hline $\mathrm{T} \times \mathrm{L}$ & 48 & $486.046,10^{\star *}$ \\
\hline $\mathrm{L} / \mathrm{T}$ & 48 & $4.916 .538,02^{\star *}$ \\
\hline Locais Linear & 1 & $211.735 .016,54^{\star \star}$ \\
\hline T x Locais Linear & 11 & $375.930,59 * \star$ \\
\hline Desvio Combinado & 36 & $561.428,55^{\star \star}$ \\
\hline Resíduo & 156 & $123.120,10$ \\
\hline \multicolumn{3}{|l|}{ Ano $1999 / 00$} \\
\hline Tratamentos $(\mathrm{T})$ & 10 & $210.692,47^{\star *}$ \\
\hline Locais (L) & 4 & $20.919 .131,81^{\star *}$ \\
\hline $\mathrm{T} \times \mathrm{L}$ & 40 & $233.029,50^{\star \star}$ \\
\hline $\mathrm{L} / \mathrm{T}$ & 44 & $2.113 .584,26^{\star \star}$ \\
\hline Locais Linear & 1 & $83.676 .527,24^{\star \star}$ \\
\hline T x Locais Linear & 10 & $375.219,17^{\star \star}$ \\
\hline Desvio Combinado & 33 & $168.757,23^{\star \star}$ \\
\hline Resíduo & 150 & $58.376,00$ \\
\hline \multicolumn{3}{|l|}{ Ano 2000/01 } \\
\hline Tratamentos $(\mathrm{T})$ & 11 & $1.036 .658,00^{\star \star}$ \\
\hline Locais (L) & 5 & $32.064 .920,90^{* *}$ \\
\hline $\mathrm{T} \times \mathrm{L}$ & 55 & $235.838,70^{* *}$ \\
\hline $\mathrm{L} / \mathrm{T}$ & 60 & $3.175 .179,13^{\star *}$ \\
\hline Locais Linear & 1 & $176.866 .252,98^{* *}$ \\
\hline Tx Locais Linear & 11 & $566.984,68^{\star \star}$ \\
\hline Desvio Combinado & 48 & $154.326,31^{* *}$ \\
\hline Resíduo & 192 & $82.237,80$ \\
\hline
\end{tabular}


A significância dos desvios combinados da regressão sugere que tanto componentes lineares e não lineares da estabilidade estão envolvidos no desempenho dos cultivares nos diversos locais.

Praticamente todos cultivares apresentaram $R^{2}$ acima de $80 \%$ (Tabelas 11 a 16), indicando que a regressão linear explicou satisfatoriamente praticamente todos os comportamentos dos cultivares frente às variações ambientais, conforme ressaltam Cruz \& Regazzi (2001).

O cultivar ideal, segundo Eberhart \& Russell (1966), será aquele que apresentar média alta, adaptabilidade ampla $\left(b_{i}=1\right)$ e alta estabilidade ou previsibilidade $\left(s_{d i}^{2}=0\right)$. Considerou-se também como cultivar mais bem adaptado àquele que expressou produtividade média superior à média geral (Mariotti et al., 1976).

As estimativas dos parâmetros de estabilidade e adaptabilidade para o sistema empresarial em 1998/99 (Tabela 11), indicam que a maioria dos cultivares apresentou adaptabilidade ampla $\left(b_{i}=1\right)$, respondendo da mesma forma tanto a ambientes favoráveis quanto desfavoráveis.

Apenas o cultivar DELTA OPAL apresentou $b_{i}>1$, indicando adaptabilidade específica para ambientes favoráveis. Porém em estudos realizados por Sobreira et al., (2003) no Estado do Mato Grosso, a estimativa de adaptabilidade obtida para este cultivar foi de $b_{i}=1$, indicando adaptabilidade ampla.

Os cultivares ITA-90 e EPAMIG PREC-1 apresentaram estimativa de $b_{i}<$ 1, sendo considerados cultivares adaptados a ambientes desfavoráveis, 
Tabela 11. Estimativas das médias de adaptabilidade $\left(b_{i}\right)$, estabilidade $\left(s_{d i}^{2}\right)$ e coeficiente de determinação $\left(R^{2}\right)$ segundo Eberhart e Russell (1966) para o caráter produtividade de algodão em caroço $(\mathrm{kg} / \mathrm{ha})$ obtido para os experimentos do Ensaio Nacional no sistema empresarial do Estado do Mato Grosso, ano agrícola 1998/99

\begin{tabular}{lcccc}
\hline Cultivares & Médias & $b_{i}$ & $s_{d i}^{2}$ & $R^{2}(\%)$ \\
\hline IAC-96/319 & $4.426,52$ & $1,08 \mathrm{~ns}$ & $-42.646,21 \mathrm{~ns}$ & 97,0 \\
DELTA OPAL & $4.336,42$ & 1,45 ** & $208.020,42$ ** & 84,2 \\
ANTARES & $4.096,58$ & $1,21 \mathrm{~ns}$ & $15.732,32 \mathrm{~ns}$ & 92,5 \\
ITA-96 & $4.058,27$ & $1,14 \mathrm{~ns}$ & $50.071,94 \mathrm{~ns}$ & 88,5 \\
DP-4049 & $4.040,10$ & $1,04 \mathrm{~ns}$ & $61.032,42 \mathrm{~ns}$ & 85,5 \\
IAC-96/280 & $4.025,56$ & $1,00 \mathrm{~ns}$ & $20.846,69 \mathrm{~ns}$ & 88,7 \\
CNPA -7H & $3.975,77$ & $0,91 \mathrm{~ns}$ & $-4.796,99 \mathrm{~ns}$ & 90,1 \\
CD-402 & $3.970,55$ & $1,01 \mathrm{~ns}$ & $119.968,51$ ** & 79,1 \\
DP-4025 & $3.750,35$ & $1,01 \mathrm{~ns}$ & $10.092,72 \mathrm{~ns}$ & 90,2 \\
CD-404 & $3.700,50$ & $1,15 \mathrm{~ns}$ & $37.700,88 \mathrm{~ns}$ & 89,9 \\
ITA-90 & $3.530,65$ & 0,52 ** & $768.962,29$ ** & 18,6 \\
EPAMIG PREC-1 & $3.497,43$ & 0,45 ** & $18.792,56 \mathrm{~ns}$ & 62,0 \\
Média & $3.950,73$ & & & \\
No Locais & 9 & & &
\end{tabular}

com baixa capacidade de responder à melhoria nas condições ambientais. Tais resultados não coincidem com aqueles observados por Sobreira et al., (2003) para ITA 90, que obtiveram uma estimativa de $b_{i}=1$; e com Machado et al., (2003) para EPAMIG PREC-1 que obtiveram $b_{i}=1$, indicando adaptabilidade ampla.

Quanto à estabilidade, medida pelos desvios da regressão $\left(s_{d i}^{2}\right)$, com exceção de DELTA OPAL, CD-402 e ITA-90, os demais cultivares foram considerados estáveis $\left(s_{d i}^{2}=0\right.$ ). Em estudo realizado por Machado et al., (2003), 
nos anos agrícolas 1990/91 a 1998/99, no Estado de Minas Gerais, o cultivar ITA-90 também apresentou comportamento instável $\left(s_{d i}^{2} \neq 0\right)$ frente as variações ambientais.Os cultivares que se destacaram em 1998/99 como ideais, portanto, com médias acima da média geral, adaptabilidade ampla $\left(b_{i}=1\right) \mathrm{e}$ comportamento previsível ou estável frente às variações ambientais $\left(s_{d i}^{2}=0\right)$ foram IAC-96/319, ANTARES, ITA-96, DP-4049, IAC-96/280 e CNPA-7H.

Comportamento semelhante foi verificado por Sobreira et al., (2003) para o cultivar ANTARES. A estabilidade fenotípica verificado para esse cultivar nessas pesquisas pode ser devida à resistência múltipla às doenças de grande importância no Centro-Oeste como viroses, bacteriose e ramulose (Freire et al., 1998).

Estudos de adaptabilidade e estabilidade fenotípica para cultivares de algodoeiro em condições de alta tecnologia são escassos na literatura. Porém, um parâmetro encontrado na literatura, utilizado para discutir e comparar com a adaptabilidade dos cultivares estudados nesta pesquisa foi àquele preconizado por Mariotti et al., (1976), onde a adaptabilidade de um determinado cultivar pode ser avaliada pelo desempenho médio dos cultivares.

Neste contexto, os cultivares IAC-96/319, DELTA OPAL, ANTARES, ITA96, DP-4049, IAC-96/280 e CNPA-7H (Tabela 11) foram considerados os mais adaptados em 1998/99, pois apresentaram produtividades médias superiores à média geral. Resultados semelhantes para esses cultivares, ou seja, produtividade média superior à média geral, foram obtidos por Fortuna et al., (1999). 
As estimativas dos parâmetros de adaptabilidade e estabilidade para o cultivar CNPA-7H (Tabela 11) estão de acordo com os resultados obtidos por Farias (1995) e por Farias et al., (1996) em estudos realizados na Região Nordeste e Centro-Oeste, respectivamente. Nestes estudos, tal cultivar apresentou boa produtividade média, porém diferiu quanto a adaptabilidade pois apresentou a estimativa de $b_{i}>1$, indicando adaptabilidade para ambientes favoráveis.

Analisando as estimativas para agricultura familiar em 1998/99 (Tabela 12), três cultivares apresentaram produtividades superiores à média geral: EPAMIG PREC-1, IAC-96/319 e DELTA OPAL. Destes, os dois primeiros cultivares apresentaram estimativas indicando adaptação ampla $\left(b_{i}=1\right)$ e comportamento previsível $\left(s_{d i}^{2}=0\right)$, sendo considerados cultivares ideais. Tal estimativa para EPAMIG PREC-1 está de acordo com Machado et al., (2003), que obteve $b_{i}=1$, indicando adaptação ampla. Já, DELTA OPAL apesar de evidenciar comportamento previsível $\left(s_{d i}^{2}=0\right)$, mostrou-se adaptado a ambientes favoráveis $\left(b_{i}>1\right)$, sendo considerado exigente.

Estes três cultivares foram avaliados por Vieira et al., (2001) em experimento de competição com outros nove cultivares, e o bom desempenho de EPAMIG PREC-1, IAC 96/319 e DELTA OPAL foi confirmado, pois todos apresentaram produtividade superior à média geral do experimento. 
Tabela 12. Estimativas das médias de adaptabilidade $\left(b_{i}\right)$, estabilidade $\left(s_{d i}^{2}\right)$ e coeficiente de determinação $\left(R^{2}\right)$ segundo Eberhart e Russell (1966) para o caráter produtividade de algodão em caroço $(\mathrm{kg} / \mathrm{ha})$ obtido para os experimentos do Ensaio Nacional na agricultura familiar do Estado do Mato Grosso, ano agrícola 1998/99

\begin{tabular}{|c|c|c|c|c|}
\hline Cultivares & Médias & $b_{i}$ & $s_{d i}^{2}$ & $R^{2}(\%)$ \\
\hline EPAMIG PREC-1 & $2.688,36$ & $0,96 \mathrm{~ns}$ & $-7.119,95 \mathrm{~ns}$ & 98,3 \\
\hline IAC-96/319 & $2.657,96$ & $1,08 \mathrm{~ns}$ & $49.837,67 \mathrm{~ns}$ & 95,5 \\
\hline DELTA OPAL & $2.488,42$ & 1,17 * & $-22.383,95 \mathrm{~ns}$ & 99,6 \\
\hline IAC-96/280 & $2.321,07$ & $0,95 \mathrm{~ns}$ & $264.746,58$ ** & 81,8 \\
\hline CNPA-7H & $2.315,34$ & $1,06 \mathrm{~ns}$ & $15.798,54 \mathrm{~ns}$ & 97,2 \\
\hline ITA-96 & $2.306,37$ & 1,22 ** & $53.372,13$ * & 96,3 \\
\hline ANTARES & $2.298,24$ & $1,12 \mathrm{~ns}$ & $84.306,24$ * & 94,2 \\
\hline ITA-90 & $2.295,86$ & $1,07 \mathrm{~ns}$ & $-7.452,16 \mathrm{~ns}$ & 98,6 \\
\hline DP-4025 & $2.292,74$ & $0,90 \mathrm{~ns}$ & $27.155,99 \mathrm{~ns}$ & 95,4 \\
\hline CD-402 & $2.283,06$ & $0,90 \mathrm{~ns}$ & $24,46 \mathrm{~ns}$ & 96,5 \\
\hline CD-404 & $2.204,53$ & $0,77^{\star *}$ & $719.787,60$ ** & 53,6 \\
\hline DP-4049 & $2.156,95$ & 0,78 * & 0,23 ** & 85,5 \\
\hline Média & $2.359,08$ & & & \\
\hline$N^{0}$ Locais & 5 & & & \\
\hline
\end{tabular}

Os cultivares que apresentaram estimativas de $b_{i}<1$ foram CD-404 e DP-4049 (Tabela 12), considerados adaptados aos ambientes desfavoráveis; no entanto suas produtividades médias foram baixas.

Resultados assim são comuns na literatura, isto é, normalmente cultivares com estimativas de adaptabilidade baixa $\left(b_{i}<1\right)$ estão associados a médias baixas. Tal fato foi confirmado para CD-404 e DP-4049, por Farias et al., (2001) e Bolonhezi et al., (1999), respectivamente, pois apresentaram 
produtividade média abaixo da média geral em experimentos de competição em experimentos.

Vale ressaltar que não foram encontrados na literatura estudos sobre adaptabilidade e estabilidade fenotípica de cultivares de algodoeiro para as condições de agricultura familiar.

Verificou-se para o cultivar CNPA-7H (Tabela 12) que, exceto para o caráter produtividade, que foi abaixo da média geral, os parâmetros de adaptabilidade e estabilidade foram semelhantes àqueles obtidos para a agricultura empresarial (Tabela 11), e também os resultados obtidos por Farias (1995) e Farias et al., (1996), indicando adaptabilidade ampla $\left(b_{i}=1\right)$ e estabilidade fenotípica $\left(s_{d i}^{2}=0\right)$. Diante desses resultados, nota-se que a estabilidade e adaptação em diversas condições são características deste cultivar.

Observando as estimativas obtidas para os cultivares avaliados em 1999/00 no sistema empresarial (Tabela 13) destacaram-se: FMT-SATURNO, BRS-743 e IAC/97-86 como ideais, com produtividades boas (acima da média geral), adaptabilidade ampla $\left(b_{i}=1\right)$ e comportamento previsível $\left(s_{d i}^{2}=0\right)$.

Um cultivar também promissor é IAPAR-97/141, que além de apresentar média alta, apresentou $b_{i}=1$ evidenciando adaptabilidade ampla. Sua desvantagem foi apresentar previsibilidade de comportamento relativamente baixa $\left(s_{d i}^{2} \neq 0\right)$. Entretanto, este cultivar não deve ser julgado como totalmente indesejável, uma vez que o seu $R^{2}$ atingiu $88,70 \%$, o que inviabiliza seu descarte, conforme relatado por Cruz \& Regazzi (2001). 
Tabela 13. Estimativas das médias de adaptabilidade $\left(b_{i}\right)$, estabilidade $\left(s_{d i}^{2}\right)$ e coeficiente de determinação $\left(R^{2}\right)$ segundo Eberhart e Russell (1966) para o caráter produtividade de algodão em caroço $(\mathrm{kg} / \mathrm{ha})$ obtido para os experimentos do Ensaio Nacional no sistema empresarial do Estado do Mato Grosso, ano agrícola 1999/00

\begin{tabular}{lcccc}
\hline Cultivares & Médias & \multicolumn{1}{c}{$b_{i}$} & $s_{d i}^{2}$ & $R^{2}(\%)$ \\
\hline FMT-SATURNO & $5.405,10$ & $0,94 \mathrm{~ns}$ & $-5.136,53 \mathrm{~ns}$ & 94,3 \\
ITA-90 & $5.326,90$ & $1,25 * *$ & $123.291,79 * *$ & 89,0 \\
IAPAR-97/141 & $5.262,20$ & $0,99 \mathrm{~ns}$ & $62.012,76 *$ & 88,7 \\
CD-402 & $5.238,90$ & $0,82 *$ & $82.303,96$ ** & 82,2 \\
BRS-743 & $5.225,50$ & $0,94 \mathrm{~ns}$ & $-5.821,00 \mathrm{~ns}$ & 94,3 \\
IAC-97/86 & 5063,50 & $0,86 \mathrm{~ns}$ & $-1.623,00 \mathrm{~ns}$ & 92,8 \\
DELTA OPAL & $4.885,60$ & $1,40 * *$ & $134.634,00 * *$ & 90,6 \\
CD-404 & $4.812,30$ & $1,13 \mathrm{~ns}$ & $5.816,00 \mathrm{~ns}$ & 95,2 \\
CNPA-8733 & $4.609,30$ & $0,98 \mathrm{~ns}$ & $49.905,00 *$ & 89,6 \\
IAC-96/319 & $4.552,80$ & 0,83 * & $31.547,00 \mathrm{~ns}$ & 88,1 \\
EPAMIG ALVA & $3.934,20$ & $0,86 \mathrm{~ns}$ & $113.176,00 * *$ & 80,4 \\
Média & $4.937,85$ & & & \\
No Locais & 12 & & & \\
\hline ,**: significativo a 5 e 1\% de probabilidade, respectivamente, pelo teste F & &
\end{tabular}

Os cultivares CD-402 e IAC/96-319 foram os menos responsivos à melhoria ambiental, apresentando estimativas de adaptabilidade menores que 1 $\left(b_{i}<1\right)$. No entanto, CD-402 apresentou boa produtividade média (acima da média geral), devendo ser avaliado com mais cuidado, pois pode ser um cultivar apropriado para ambientes inferiores.

O cultivar ITA-90 apresentou elevado rendimento médio, o que o torna recomendável a ambientes que utilizam recursos (naturais ou artificiais) para elevar a produtividade. Os cultivares DELTA OPAL e ITA-90, apresentaram 
estimativa de $b_{i}>1$ sendo adaptados aos ambientes favoráveis, ou seja, condições de elevada tecnologia. Quanto à estabilidade ambos foram considerados com comportamento instável $\left(s_{d i}^{2} \neq 0\right)$. A instabilidade de ITA-90 mediante as variações ambientais pode ser devido à susceptibilidade às doenças (viroses) conforme se verificou em trabalho de estabilidade realizado por Fuzatto et al., (1994).

Avaliando os parâmetros obtidos para os cultivares em 1999/00 para o sistema de agricultura familiar (Tabela 14), nota-se que IAPAR-97/141 apresentou boa produtividade (acima da média geral), apresentou adaptabilidade ampla $\left(b_{i}=1\right)$ e também mostrou-se estável $\left(s_{d i}^{2}=0\right)$. Freitas et al., (2001), avaliando a competição de produtividade entre 12 cultivares, verificou que IAPAR-97/141 foi o cultivar de maior rendimento médio. Estes resultados confirmam a boa adaptabilidade deste cultivar.

Os cultivares IAC-97/86, FMT-SATURNO e BRS-743 e ITA 90 (Tabela 14) mostraram-se adaptados aos ambientes favoráveis $\left(b_{i}>1\right)$ e destacaram devido alta produtividade. À exceção de IAC-97/86, os demais cultivares evidenciaram estabilidade ampla no comportamento fenotípico frente às variações ambientais $\left(s_{d i}^{2}=0\right)$.

Uma atenção maior deve ser dada ao cultivar EPAMIG ALVA, altamente produtivo e adaptado a ambientes desfavoráveis, mas com instabilidade de resposta $\left(s_{d i}^{2} \neq 0\right)$. Contudo, Ribeiro et al., (2003), em experimentos de 
Tabela 14. Estimativas das médias de adaptabilidade $\left(b_{i}\right)$, estabilidade $\left(s_{d i}^{2}\right)$ e coeficiente de determinação $\left(R^{2}\right)$ segundo Eberhart e Russell (1966) para o caráter produtividade de algodão em caroço $(\mathrm{kg} / \mathrm{ha})$ obtido para os experimentos do Ensaio Nacional na agricultura familiar do Estado do Mato Grosso, ano agrícola 1999/00

\begin{tabular}{lcccc}
\hline Cultivares & Médias & \multicolumn{1}{c}{$b_{i}$} & $s_{d i}^{2}$ & $R^{2}(\%)$ \\
\hline IAC-97/86 & $2.029,80$ & $1,24 * *$ & $29.822,00 *$ & 95,6 \\
EPAMIG ALVA & $1.988,50$ & $0,79 *$ & $90.145,00$ ** & 79,2 \\
FMT-SATURNO & $1.945,20$ & $1,21 *$ & $13.526,00 \mathrm{~ns}$ & 97,1 \\
BRS-743 & $1.939,50$ & $1,25 * \star$ & $15.033,00 \mathrm{~ns}$ & 97,1 \\
IAPAR-97/141 & $1.898,80$ & $1,07 \mathrm{~ns}$ & $-129,00 \mathrm{~ns}$ & 98,0 \\
ITA-90 & $1.856,35$ & $1,17 *$ & $97.782,00 * *$ & 88,6 \\
CD-402 & $1.853,50$ & $1,04 \mathrm{~ns}$ & $-6.225,00 \mathrm{~ns}$ & 98,8 \\
CD-404 & $1.807,75$ & $0,88 \mathrm{~ns}$ & $20.552,00 \mathrm{~ns}$ & 93,3 \\
DELTA OPAL & $1.794,25$ & $0,93 \mathrm{~ns}$ & $51.215,00 * *$ & 89,2 \\
CNPA-8733 & $1.742,05$ & $0,54 * *$ & $-1.551,00 \mathrm{~ns}$ & 93,4 \\
IAC-96/319 & $1.702,60$ & $0,87 \mathrm{~ns}$ & $-6.622,00 \mathrm{~ns}$ & 98,4 \\
Média & 1868,11 & & & \\
No Locais & 5 & & & \\
*,**: significativo a 5 e 1\% de probabilidade, respectivamente, pelo teste F &
\end{tabular}

competição com outros cultivares, obteve para este cultivar uma produtividade 9\% inferior à média geral.

Para o ano 2000/01, no sistema empresarial (Tabela 15), apenas IPR-94 uniu as estimativas preconizadas por Eberhart \& Russell (1966) como cultivar ideal (média alta, $b_{i}=1$ e $s_{d i}^{2}=0$ ).

Os cultivares DELTA OPAL, BRS-97/1682, IPR-96 e BRS CEDRO destacaram-se devido à boa produtividade (acima da média geral) e evidenciaram adaptação aos ambientes favoráveis $\left(b_{i}>1\right)$, mostrando-se cultivares capazes de responder às melhorias ambientais. Destes, IPR-96 e 
Tabela 15. Estimativas das médias de adaptabilidade $\left(b_{i}\right)$, estabilidade $\left(s_{d i}^{2}\right)$ e coeficiente de determinação $\left(R^{2}\right)$ segundo Eberhart e Russell (1966) para o caráter produtividade de algodão em caroço $(\mathrm{kg} / \mathrm{ha})$ obtido para os experimentos do Ensaio Nacional na agricultura empresarial no Estado do Mato Grosso, ano agrícola 2000/01

\begin{tabular}{lcccc}
\hline Cultivares & Médias & \multicolumn{1}{c}{$b_{i}$} & $s_{d i}^{2}$ & $R^{2}(\%)$ \\
\hline DELTA OPAL & $4.345,77$ & 1,24 ** & $79.695,00 *$ & 96,7 \\
IPR-94 & $4.314,46$ & $1,06 \mathrm{~ns}$ & $19.400,00 \mathrm{~ns}$ & 97,4 \\
BRS-97/1682 & $4.234,48$ & $1,25 * *$ & $137.783,00 * *$ & 95,4 \\
IPR-96 & $4.148,15$ & $1,12 *$ & $46.350,00 \mathrm{~ns}$ & 96,9 \\
CNPA/96-1202 & $4.122,36$ & $0,93 \mathrm{~ns}$ & $133.736,00 * *$ & 92,1 \\
BRS CEDRO & $4.091,14$ & $1,23 * *$ & $51.032,00 \mathrm{~ns}$ & 97,3 \\
IAC-97/86 & $4.084,56$ & $0,75 * *$ & $113.955,00 * *$ & 89,6 \\
ITA-90 & $3.915,09$ & $1,10 \mathrm{~ns}$ & $439.809,00 * *$ & 86,6 \\
BRS-201 & $3.913,86$ & $1,04 \mathrm{~ns}$ & $87.256,00 *$ & 95,1 \\
FMT-SATURNO & $3.863,76$ & $0,84 * *$ & $231.082,00 * *$ & 86,6 \\
DP-4049 & $3.830,98$ & $1,03 \mathrm{~ns}$ & $134.511,00 * *$ & 93,5 \\
EPAMIG LIÇA & $2.633,81$ & $0,38 * *$ & $64.709,00 *$ & 75,7 \\
Média & $3.958,09$ & & & \\
No Locais & 9 & & & \\
***: significativo a 5 e 1\% de probabilidade, respectivamente, pelo teste F & &
\end{tabular}

BRS CEDRO mostraram estáveis $\left(s_{d i}^{2}=0\right)$, sendo, portanto, indicados para ambientes altamente favoráveis.

Em 2000/01, observando os cultivares avaliados nas condições de agricultura familiar (Tabela 16), somente IPR 96 e DP 4049 foram considerados 
Tabela 16. Estimativas das médias de adaptabilidade $\left(b_{i}\right)$, estabilidade $\left(s_{d i}^{2}\right)$ e coeficiente de determinação $\left(R^{2}\right)$ segundo Eberhart e Russell (1966) para o caráter produtividade de algodão em caroço $(\mathrm{kg} / \mathrm{ha})$ obtido para os experimentos do Ensaio Nacional na agricultura familiar no Estado do Mato Grosso, ano agrícola 2000/01

\begin{tabular}{lcccc}
\hline Cultivares & Médias & $b_{i}$ & $s_{d i}^{2}$ & $R^{2}(\%)$ \\
\hline IAC-97/86 & $3.054,61$ & 1,20 ** & $67.130,09$ ** & 93,9 \\
IPR-96 & $2.960,25$ & $1,10 \mathrm{~ns}$ & $8.959,18 \mathrm{~ns}$ & 97,5 \\
BRS CEDRO & $2.915,46$ & $1,13 \mathrm{~ns}$ & $39.520,52 *$ & 95,1 \\
IPR-94 & $2.906,17$ & $0,81 *$ & $4.030,61 \mathrm{~ns}$ & 96,1 \\
DP-4049 & $2.859,54$ & $1,08 \mathrm{~ns}$ & $-17.967,58 \mathrm{~ns}$ & 99,8 \\
BRS-201 & $2.824,33$ & 1,20 ** & $-12.521,38 \mathrm{~ns}$ & 99,4 \\
FMT-SATURNO & $2.753,18$ & $0,93 \mathrm{~ns}$ & $49.720,86$ ** & 91,9 \\
CNPA-96/1202 & $2.749,25$ & $0,99 \mathrm{~ns}$ & $14.830,59 \mathrm{~ns}$ & 96,3 \\
DELTA OPAL & $2.642,75$ & $1,13 \mathrm{~ns}$ & $-2.139,92 \mathrm{~ns}$ & 98,5 \\
ITA-90 & $2.629,59$ & $0,84 *$ & $-11.939,86 \mathrm{~ns}$ & 98,7 \\
BRS-97/1682 & $2.615,86$ & $1,02 \mathrm{~ns}$ & $2.632,88 \mathrm{~ns}$ & 97,6 \\
EPAMIG LIÇA & $2.262,45$ & 0,53 ** & $74.011,94$ ** & 73,5 \\
Média & $2.764,45$ & & & \\
№ Locais & 6 & & & \\
****: significativo a 5 e 1\% de probabilidade, respectivamente, pelo teste F & &
\end{tabular}

ideais segundo esta metodologia (média alta, $b_{i}=1$ e $s_{d i}^{2}=0$ ). BRS CEDRO se destacou quanto à produtividade e adaptação a todos os ambientes $\left(b_{i}=1\right)$; contudo apresentou $s_{d i}^{2} \neq 0$ evidenciando instabilidade fenotípica, mas de grau não muito elevado, visto que o $R^{2}$ foi igual a 95,1\%.

O cultivar IPR-94 aliou alta produtividade, adaptação a ambientes desfavoráveis $\left(b_{i}<1\right)$ e estabilidade alta $\left(s_{d i}^{2}=0\right)$, sendo portanto recomendado para ambientes desfavoráveis. Em experimentos de competição realizado no 
Estado de São Paulo em 2000/01 por Cia et al., (2003), IPR-94 se destacou entre 12 cultivares avaliados, como um dos cultivares mais produtivos.

Para os cultivares avaliados em um mesmo ano, mas em sistemas de produção diferentes, notou-se também um comportamento não consistente quanto à produtividade e aos parâmetros de adaptabilidade e estabilidade.

No ano agrícola 1998/99 (Tabelas 11 e 12), por exemplo, dos 12 cultivares avaliados no sistema empresarial e familiar, nove apresentaram estimativas diferentes em pelo menos um dos parâmetros, e apenas IAC 96319, DP 4025 e CNPA-7H mantiveram comportamento consistente nos dois sistemas.

Em 1999/00 (Tabelas 13 e 14) dos 11 cultivares avaliados, somente ITA 90 apresentou comportamento consistente nos dois sistemas, com adaptabilidade aos ambientes favoráveis e instabilidade fenotípica em ambas situações.

Já em 2000/01 (Tabelas 15 e 16), dos 12 cultivares avaliados, EPAMIG ALVA foi o único que não apresentou comportamento diferenciado quanto à estabilidade e adaptabilidade, e tampouco quanto ao desempenho produtivo em relação aos demais cultivares, sendo o menos produtivo nos dois sistemas.

Mediante tais observações, nota-se de maneira geral que os cultivares de destaque no sistema empresarial não foram os mesmos que no sistema de agricultura familiar, indicando que seus comportamentos não são consistentes nos ambientes diferentes (locais e sistemas de produção).

Tais discrepâncias são esperadas, pois, de acordo com o descrito por Crossa (1990), os resultados das estimativas de adaptabilidade e estabilidade 
são relativos aos ambientes e ao grupo de cultivares envolvidos, não podendo ser generalizados indicando que um cultivar estável num determinado grupo não o será necessariamente em outro. Percebe-se então que a comparação da estabilidade dos cultivares é bastante complexa e relativa.

Dessa forma, a escolha e substituição dos cultivares nos experimentos de agricultura empresarial e familiar a cada ano requer critérios específicos, ou seja, para cada sistema é necessário que o melhorista considere os aspectos particulares que influenciarão no comportamento do cultivar e na escolha deste pelo agricultor. Freire et al., (1998) comenta alguns desses aspectos: tipo de produtor (pequeno, médio ou grande), sua experiência com a cultura do algodão, nível de tecnologia utilizado na condução da lavoura (simples, média ou alta) e conhecimento sobre as doenças que ocorrem na região.

Por tais motivos, é necessária muita atenção na escolha dos cultivares, pois as diferenças ambientais afetam os diferentes cultivares de maneiras diferentes.

Entretanto, observou-se nesta pesquisa que os critérios utilizados foram os mesmos para os dois sistemas de produção (empresarial e familiar), pois a composição e substituição do grupo de cultivares foram idênticas, como pode ser verificado nas Tabelas 11 a 16.

Outro aspecto importante a ser considerado é que, os cultivares avaliados no sistema familiar deveriam ser mantidos por mais anos nos experimentos, pois as interações cultivares $x$ locais $x$ anos poderiam ser mais bem detalhadas com vista à recomendação. Neste sentido Rosse (1999) menciona que para o pequeno agricultor, é mais interessante que os cultivares apresentem, ao longo 
dos anos, boa estabilidade e produtividade, ou seja, baixas interações com as flutuações climáticas existentes entre anos, denominado por Vencovsky \& Torres (1988) como estabilidade temporal, ao invés da adaptabilidade geográfica. Assim, a rotatividade dos cultivares nos experimentos para o sistema familiar deveria ser diferente do sistema empresarial. Isso, porém, não vem ocorrendo, pois de modo geral nos programas de melhoramento é dada maior ênfase à adaptabilidade geográfica do que à estabilidade diante das flutuações anuais. 


\section{CONCLUSÕES}

1) Existe interação entre cultivares e locais nos sistemas de produção empresarial e familiar, indicando que o comportamento dos cultivares não foi consistente nos diferentes locais;

2) A interação é predominantemente do tipo complexo, isto é devida à falta de correlação entre as performances dos cultivares nos diferentes locais;

3) Os cultivares adaptados, estáveis e produtivos de produção empresarial não foram os mesmos no sistema de agricultura familiar.

4) A avaliação e substituição de cultivares nos experimentos de um programa de melhoramento do algodoeiro devem possuir critérios específicos para cada sistema, empresarial ou familiar. 
ANEXOS 
Anexo A. Médias e resumos das análises de variância individuais para o caráter produtividade de algodão em caroço (kg/ha), obtido dos experimentos do Ensaio Nacional de algodoeiro herbáceo para agricultura empresarial no Estado do Mato Grosso, no ano agrícola 1998/99

\begin{tabular}{|c|c|c|c|c|c|c|c|c|c|c|}
\hline \multirow{2}{*}{ Tratamentos } & \multicolumn{10}{|c|}{ Municípios } \\
\hline & Rondonópolis & Alto Taquari & Pedra Preta & $\begin{array}{l}\text { Campo } \\
\text { Verde }\end{array}$ & $\begin{array}{l}\text { Primavera do } \\
\text { Leste }\end{array}$ & Nova Mutum & $\begin{array}{c}\text { Campo Novo } \\
\text { do Parecis }\end{array}$ & Sapezal & $\begin{array}{l}\text { Lucas do Rio } \\
\text { Verde }\end{array}$ & Médias \\
\hline CD-404 & 4490,10 & 3966,36 & 5257,53 & 2935,49 & 4700,49 & 3261,41 & 3283,71 & 2435,47 & 2973,97 & $3.700,50$ \\
\hline IAC-96/280 & 4461,55 & 3999,56 & 4898,06 & 3192,05 & 5601,54 & 3532,64 & 3588,54 & 3853,09 & 3103,01 & $4.025,56$ \\
\hline CNPA -7H & 4822,30 & 3955,20 & 5119,18 & 3171,42 & 4751,44 & 3769,35 & 3566,80 & 3470,80 & 3155,45 & $3.975,77$ \\
\hline ANTARES & 4267,80 & 4799,09 & 5298,80 & 3045,05 & 5714,21 & 3657,75 & 3349,75 & 3695,44 & 3041,40 & $4.096,59$ \\
\hline DELTA OPAL & 5167,31 & 5213,22 & 6597,48 & 3267,81 & 5127,63 & 3726,18 & 3486,26 & 3605,81 & 2836,05 & $4.336,42$ \\
\hline EPAMIG PREC-1 & 3845,06 & 3159,33 & 3867,83 & 3074,27 & 4193,17 & 3506,31 & 3442,29 & 3618,89 & 2769,73 & $3.497,43$ \\
\hline IAC/96-319 & 5040,82 & 4777,52 & 5442,45 & 3369,47 & 5739,43 & 4068,74 & 3946,49 & 3923,67 & 3530,08 & $4.426,51$ \\
\hline DP-4025 & 4530,33 & 4089,12 & 4934,09 & 2431,52 & 4547,66 & 3591,23 & 3493,72 & 3136,28 & 2999,22 & $3.750,35$ \\
\hline ITA- 90 & 1925,16 & 4294,26 & 3451,32 & 2974,32 & 5360,94 & 3896,40 & 3486,99 & 3164,44 & 3222,05 & $3.530,65$ \\
\hline ITA- 96 & 4285,22 & 3878,50 & 5465,40 & 3306,30 & 5737,65 & 3776,84 & 3162,26 & 3689,42 & 3222,89 & $4.058,27$ \\
\hline CD-402 & 4548,51 & 4005,77 & 5290,87 & 3163,12 & 4877,90 & 3837,75 & 4197,22 & 2474,97 & 3338,88 & $3.970,55$ \\
\hline DP-4049 & 4412,93 & 4189,61 & 5361,19 & 3051,18 & 5063,59 & 4028,98 & 4185,61 & 2689,22 & 3378,56 & $4.040,10$ \\
\hline QM TRATAMENTOS & $2.766 .716,30^{\star *}$ & $1.134 .058,88^{\star \star}$ & $2.532 .150,7^{* *}$ & * $237.354,80$ * & $1.079 .425,30 \mathrm{~ns}$ & $210.648,90 \mathrm{~ns}$ & $449.834,70^{\star}$ & $912.784,80^{\star *}$ & $199.798,50 \mathrm{~ns}$ & - \\
\hline QM RESÍDUO & $249.165,70$ & $318.952,20$ & $322.466,48$ & $110.494,80$ & $616.508,20$ & $193.196,30$ & $199.132,70$ & $305.330,60$ & $109.103,10$ & - \\
\hline MÉDIAS & $4.316,20$ & $4.194,00$ & $5.082,00$ & $3.081,80$ & $5.117,90$ & $3.721,10$ & $3.599,10$ & $3.385,10$ & $3.130,90$ & - \\
\hline $\mathrm{CV}(\%)$ & 11,56 & 13,46 & 11,17 & 10,78 & 15,34 & 11,81 & 12,40 & 16,32 & 10,55 & 13,07 \\
\hline
\end{tabular}


Anexo B. Médias e resumos das análises de variância individuais para o caráter produtividade de algodão em caroço (kg/ha), obtido dos experimentos do Ensaio Nacional de algodoeiro herbáceo para agricultura empresarial no Estado do Mato Grosso, no ano agrícola 1999/00

\begin{tabular}{|c|c|c|c|c|c|c|}
\hline \multirow[b]{2}{*}{ Tratamentos } & \multicolumn{6}{|c|}{ Municípios } \\
\hline & Rondonópolis & Itiquira & Pedra Preta & Alto Taquari & Campo Verde & $\begin{array}{c}\text { Primavera do } \\
\text { Leste }\end{array}$ \\
\hline FMT-SATURNO & 4669,71 & 6735,50 & 6545,54 & 6691,33 & 5665,32 & 5091,21 \\
\hline BRS-743 & 4704,52 & 6820,53 & 5967,07 & 6552,01 & 5753,39 & 4823,66 \\
\hline IAC/97-86 & 4197,42 & 6195,34 & 6140,35 & 6151,49 & 5534,30 & 4973,96 \\
\hline DELTA OPAL & 4562,36 & 7143,84 & 6249,58 & 7038,15 & 5699,18 & 3930,74 \\
\hline CD-402 & 4516,19 & 6027,00 & 5860,12 & 6405,45 & 5835,37 & 4404,04 \\
\hline CNPA-8733 & 3520,33 & 5843,41 & 5945,97 & 5531,85 & 5510,19 & 3415,59 \\
\hline CD-404 & 4156,07 & 6714,18 & 5973,78 & 6224,05 & 5682,98 & 3934,61 \\
\hline IAPAR/97-141 & 4400,85 & 6937,06 & 6392,98 & 6502,68 & 5630,90 & 4275,31 \\
\hline IAC/96-319 & 4161,15 & 5450,80 & 5700,57 & 5762,58 & 5424,44 & 4364,17 \\
\hline EPAMIG ALVA & 3515,25 & 4473,94 & 5119,59 & 5063,12 & 4566,55 & 3218,30 \\
\hline ITA-90 & 3599,56 & 6615,55 & 6738,50 & 7014,93 & 6536,85 & 5257,90 \\
\hline QM TRATAMENTOS & $815.234,95^{\star \star}$ & $2.475 .409,59^{\star *}$ & $772.760,90^{\star \star}$ & $1.499 .791,55^{\star \star}$ & $833.822,36$ ns & $1.798 .362,99 * *$ \\
\hline QM RESÍDUO & $83.300,59$ & $254.964,72$ & $133.876,98$ & $156.485,03$ & $393.163,45$ & $197.521,84$ \\
\hline MÉDIAS & $4.182,13$ & $6.268,83$ & $6.057,64$ & $6.267,06$ & $5.621,77$ & $4.335,41$ \\
\hline $\mathrm{CV}(\%)$ & 6,90 & 8,05 & 6,04 & 6,31 & 11,15 & 10,25 \\
\hline
\end{tabular}


Anexo C. Médias e resumos das análises de variância individuais para o caráter produtividade de algodão em caroço ( $\mathrm{kg} / \mathrm{ha}$ ), obtido dos experimentos do Ensaio Nacional de algodoeiro herbáceo para agricultura empresarial no Estado do Mato Grosso, no ano agrícola 1999/00

\begin{tabular}{|c|c|c|c|c|c|c|c|}
\hline \multirow[b]{2}{*}{ Tratamentos } & \multicolumn{7}{|c|}{ Municípios } \\
\hline & $\begin{array}{l}\text { Campo Novo } \\
\text { do Parecis } 1\end{array}$ & $\begin{array}{l}\text { Campo Novo } \\
\text { do Parecis } 2\end{array}$ & Sapezal & Nova Mutum & $\begin{array}{l}\text { Lucas do Rio } \\
\text { Verde }\end{array}$ & Sorriso & Médias $^{1}$ \\
\hline FMT-SATURNO & 5291,31 & 5473,50 & 5212,95 & 4913,97 & 3802,06 & 4768,53 & $5.405,07$ \\
\hline BRS-743 & 4929,85 & 5457,87 & 4904,29 & 4417,65 & 4154,69 & 4219,99 & $5.225,46$ \\
\hline IAC/97-86 & 4401,39 & 5265,41 & 5079,00 & 4273,11 & 3829,63 & 4720,64 & $5.063,50$ \\
\hline DELTA OPAL & 4333,55 & 4594,24 & 4791,42 & 3122,72 & 3566,97 & 3594,54 & $4.885,60$ \\
\hline CD-402 & 4675,14 & 5958,40 & 5934,63 & 4737,66 & 3912,34 & 4600,20 & $5.238,88$ \\
\hline CNPA-8733 & 4647,65 & 5058,77 & 4422,41 & 3986,84 & 3372,51 & 4056,01 & $4.609,29$ \\
\hline CD-404 & 4238,53 & 4534,19 & 4886,84 & 4010,48 & 3542,30 & 3849,95 & $4.812,33$ \\
\hline IAPAR/97-141 & 4872,35 & 5051,70 & 5774,52 & 4910,67 & 4169,20 & 4228,70 & $5.262,24$ \\
\hline IAC/96-319 & 3815,74 & 4210,36 & 4347,51 & 3877,72 & 3391,38 & 4127,12 & $4.552,79$ \\
\hline EPAMIG ALVA & 4142,95 & 4799,01 & 3462,48 & 3321,99 & 2342,18 & 3185,31 & $3.934,22$ \\
\hline ITA-90 & 5283,76 & 5733,57 & 4882,16 & 4041,26 & 3706,28 & 4513,13 & $5.326,95$ \\
\hline QM TRATAMENTOS & $880.521,64^{\star \star}$ & $1.158 .036,24^{\star *}$ & $1.829 .443,00 * *$ & $1.043 .027,64^{\star \star}$ & $1.005 .043,95$ ** & $955.293,99 * \star$ & - \\
\hline QM RESÍDUO & $182.167,32$ & $337.344,53$ & $235.474,83$ & $283.664,50$ & $258.347,89$ & $123.586,64$ & - \\
\hline MÉDIAS & $4.602,93$ & $5.103,36$ & $4.881,65$ & $4.147,66$ & $3.617,23$ & $4.169,46$ & - \\
\hline CV(\%) & 9,27 & 11,38 & 9,94 & 12,84 & 14,05 & 8,43 & 10,99 \\
\hline
\end{tabular}


Anexo D. Médias e resumos das análises de variância individuais para o caráter produtividade de algodão em caroço (kg/ha), obtido dos experimentos do Ensaio Nacional de algodoeiro herbáceo para agricultura empresarial no Estado do Mato Grosso, no ano agrícola 2000/01

\begin{tabular}{|c|c|c|c|c|c|c|c|c|c|c|}
\hline \multirow{2}{*}{ Tratamentos } & \multicolumn{10}{|c|}{ Municípios } \\
\hline & Rondonópolis & Campo Verde & Pedra Preta & Sapezal & Sorriso & $\begin{array}{c}\text { Primavera do } \\
\text { Leste }\end{array}$ & $\begin{array}{c}\text { Novo São } \\
\text { Joaquim }\end{array}$ & $\begin{array}{c}\text { Campo Novo } \\
\text { do Parecis }\end{array}$ & $\begin{array}{c}\text { Lucas do Rio } \\
\text { Verde }\end{array}$ & Médias \\
\hline CNPA/ 96-1202 & 5018.95 & 5613.33 & 5459.18 & 2569.19 & 5724.43 & 2871.94 & 4637.87 & 3269.12 & $1.937,27$ & $4.122,36$ \\
\hline BRS-201 & 5162,60 & 5331.42 & 6039.68 & 1581.38 & 5229.48 & 2771.95 & 3996.27 & 3114.97 & $1.996,98$ & $3.913,81$ \\
\hline BRS CEDRO & 4442.62 & 5727.21 & 6886.81 & 1148,86 & 5553.61 & 3087.19 & 4797.58 & 3381.61 & $1.794,80$ & $4.091,14$ \\
\hline DELTA OPAL & 4723,76 & 6025.79 & 7753.91 & 2244.22 & 5549.45 & 2939.99 & 4794.80 & 3030.26 & $2.049,80$ & $4.345,77$ \\
\hline DP-4049 & 4379,35 & 4664.81 & 6291.02 & 1222.1 & 5389.74 & 2484.48 & 4222.91 & 3530.21 & $2.294,22$ & $3.830,98$ \\
\hline IAC/97-86 & 4863.41 & 5260.59 & 5267.53 & 3124.69 & 5384.19 & 2948.32 & 4446.22 & 3227.46 & $2.238,67$ & $4.084,56$ \\
\hline IPR-94 & 5050.89 & 6118.84 & 6239.81 & 1874.81 & 5721.65 & 3302.45 & 4708.42 & 3513.54 & $2.299,70$ & $4.314,46$ \\
\hline IPR-96 & 4406.51 & 5652.22 & 6808.85 & 1365.72 & 5541.12 & 2996.93 & 4493.16 & 3645.47 & $2.423,37$ & $4.148,15$ \\
\hline EPAMIG LIÇA & 2181,42 & 3587.15 & 3784.35 & 2152.56 & 2987.20 & 1976.19 & 2464.48 & 2445.59 & $2.125,32$ & $2.633,81$ \\
\hline FMT-SATURNO & 4956.45 & 5588.33 & 4931.97 & 2489.94 & 5173.10 & 2174.79 & 4201.80 & 2912.21 & $2.345,25$ & $3.863,76$ \\
\hline BRS/97-1682 & 4029.38 & 6175.77 & 7685.33 & 2045.54 & 5584.17 & 2396.99 & 4539.55 & 3271.90 & $2.381,71$ & $4.234,48$ \\
\hline ITA -90 & 2712.85 & 6066.06 & 6605.87 & 2050.84 & 5281.42 & 2590.02 & 4991.72 & 2809.44 & $2.127,57$ & $3.915,09$ \\
\hline QM TRATAMENTOS & $2.728 .041,94^{\star \star}$ & $2.171 .372,73^{\star \star}$ & $4.586 .211,20^{\star \star}$ & $1.204 .931,53^{\star \star}$ & $2.178 .080,24^{\star *}$ & $619.445,31^{\star \star}$ & $1.747 .156,56^{\star \star}$ & $467.226,17^{\star}$ & $106.456,93 \mathrm{~ns}$ & - \\
\hline QM RESÍDUO & $294.446,50$ & $376.456,88$ & $615.198,38$ & $88.600,68$ & $269.363,78$ & $115.081,22$ & $73.523,96$ & $215.373,93$ & $66.474,08$ & - \\
\hline MÉDIAS & $4.380,65$ & $5.484,29$ & $6.059,42$ & $2.019,17$ & $5.260,96$ & $2.711,77$ & $4.357,90$ & $3.179,31$ & $2.193,67$ & - \\
\hline $\mathrm{CV}(\%)$ & 12,38 & 11,18 & 12,94 & 14,74 & 9,87 & 12,51 & 6,22 & 14,60 & 11,75 & 11,80 \\
\hline
\end{tabular}


Anexo E. Médias e resumos das análises de variância individuais para o caráter produtividade de algodão em caroço (kg/ha), obtido dos experimentos do Ensaio Nacional de algodoeiro herbáceo para agricultura familiar no Estado do Mato Grosso, no ano agrícola 1998/99

\begin{tabular}{lcccccc}
\hline \multirow{2}{*}{ Tratamentos } & \multicolumn{7}{c}{ Municípios } \\
\cline { 2 - 7 } & Cáceres & Sinop & $\begin{array}{c}\text { Tangará da } \\
\text { Serra }\end{array}$ & $\begin{array}{c}\text { Pontes e } \\
\text { Lacerda }\end{array}$ & $\begin{array}{c}\text { São José dos } \\
\text { Quatro Marcos }\end{array}$ & Médias \\
\hline CD-404 & $3.665,67$ & $2.351,15$ & $2.602,26$ & 688,20 & $1.715,36$ & $2.204,53$ \\
IAC/96-280 & $2.502,74$ & $2.116,05$ & $2.375,89$ & 757,58 & $3.853,09$ & $2.321,07$ \\
CNPA-7H & $2.862,46$ & $1.984,21$ & $2.735,76$ & 534,19 & $3.460,09$ & $2.315,39$ \\
ANTARES & $2.950,55$ & $2.080,08$ & $2.337,80$ & 427,35 & $3.695,44$ & 2.298 .25 \\
DELTA OPAL & $3.352,14$ & $2.104,10$ & $2.844,48$ & 535,58 & $3.605,81$ & $2.488,42$ \\
EPAMIG PREC-1 & $3.469,10$ & $2.231,41$ & $2.970,79$ & $1.151,62$ & $3.618,89$ & $2.688,36$ \\
IAC/96-319 & $3.149,57$ & $2.308,33$ & $3.056,31$ & 851,93 & $3.923,68$ & $2.657,96$ \\
DP/4025 & $3.286,47$ & $2.091,01$ & $2.579,79$ & 729,83 & $2.776,61$ & $2.292,74$ \\
ITA-90 & $3.023,98$ & $1.970,30$ & $2.875,21$ & 445,39 & $3.164,44$ & $2.295,86$ \\
ITA-96 & $3.103,18$ & $2.111,25$ & $2.376,88$ & 251,14 & $3.689,42$ & $2.306,37$ \\
CD-402 & $3.084,10$ & $2.020,93$ & $2.800,06$ & 710,40 & $2.799,81$ & $2.283,06$ \\
DP-4049 & $3.127,48$ & $1.942,08$ & $2.649,33$ & 756,61 & $2.309,26$ & $2.156,95$ \\
QM TRATAMENTOS & $330.414,87^{\star *}$ & $61.472,63 \mathrm{~ns}$ & $225.501,76 *$ & $218.477,41^{\star *}$ & $1.657 .787,82^{\star *}$ & - \\
QM RESÍDUO & $76.633,95$ & $43.415,38$ & $57.665,79$ & $36.160,71$ & $405.141,68$ & - \\
MÉDIAS & $3.125,08$ & $2.105,53$ & $2.675,24$ & 648,64 & $3.340,69$ & - \\
CV(\%) & 8,85 & 9,89 & 8,97 & 29,31 & 19,64 & 14,73 \\
\hline
\end{tabular}


Anexo F. Médias e resumos das análises de variância individuais para o caráter produtividade de algodão em caroço ( $\mathrm{kg} / \mathrm{ha}$ ), obtido dos experimentos do Ensaio Nacional de algodoeiro herbáceo para a agricultura familiar no Estado do Mato Grosso, no ano agrícola 1999/00

\begin{tabular}{lcccccc}
\hline \multirow{7}{*}{ Tratamentos } & \multicolumn{7}{c}{ Municípios } \\
\cline { 2 - 7 } & Cáceres & $\begin{array}{c}\text { São José dos } \\
\text { Quatro } \\
\text { Marcos }\end{array}$ & $\begin{array}{c}\text { Glória } \\
\text { D'Oeste }\end{array}$ & $\begin{array}{c}\text { Pontes e } \\
\text { Lacerda }\end{array}$ & Sinop & Médias \\
\hline FMT-SATURNO & $2.137,50$ & $3.311,25$ & $1.129,25$ & $1.730,00$ & $1.418,00$ & $1.945,20$ \\
BRS-743 & $2.090,25$ & $3.405,00$ & $1.375,50$ & $1.318,75$ & $1.508,00$ & $1.939,50$ \\
IAC/97-86 & $2.212,50$ & $3.462,50$ & $1.443,00$ & $1.305,00$ & $1.726,00$ & $2.029,80$ \\
DELTA OPAL & $2.394,75$ & $2.637,50$ & $1.109,75$ & $1.468,75$ & $1.360,50$ & $1.794,25$ \\
CD-402 & $2.108,25$ & $3.020,00$ & $1.351,50$ & $1.391,25$ & $1.396,50$ & $1.853,50$ \\
CNPA/8733 & $2.035,00$ & $2.255,00$ & $1.338,75$ & $1.536,25$ & $1.545,25$ & $1.742,05$ \\
CD-404 & $1.765,25$ & $2.897,50$ & $1.406,75$ & $1.548,75$ & $1.420,50$ & $1.807,75$ \\
IAPAR/97-141 & $2.218,25$ & $3.023,75$ & $1.108,25$ & $1.613,25$ & $1.530,50$ & $1.898,80$ \\
IAC/96-319 & $2.022,00$ & $2.606,25$ & $1.103,75$ & $1.348,75$ & $1.432,25$ & $1.702,60$ \\
EPAMIG ALVA & $2.546,00$ & $2.655,00$ & $1.166,50$ & $1.790,00$ & $1.785,00$ & $1.988,50$ \\
ITA-90 & $1.705,50$ & $3.375,00$ & $1.455,50$ & $1.371,25$ & $1.374,50$ & $1.856,35$ \\
QM TRATAMENTOS & $236.134,44^{* *}$ & $630.472,96^{* *}$ & $86.205,10^{*}$ & $110.438,36 *$ & $79.559,62^{*}$ & - \\
QM RESÍDUO & $54.543,84$ & $122.873,41$ & $37.113,47$ & $50.545,46$ & $26.805,91$ & - \\
MÉDIAS & $2.112,30$ & $2.958,07$ & $1.271,68$ & $1.492,91$ & $1.499,73$ & - \\
CV (\%) & 11,06 & 11,81 & 15,15 & 15,05 & 10,92 & 12,80 \\
\hline
\end{tabular}


Anexo G. Médias e resumos das análises de variância individuais para o caráter produtividade de algodão em caroço (kg/ha), obtido dos experimentos do Ensaio Nacional de algodoeiro herbáceo para a agricultura familiar no Estado do Mato Grosso, no ano agrícola 2000/01

\begin{tabular}{|c|c|c|c|c|c|c|c|}
\hline \multirow[b]{2}{*}{ Tratamentos } & \multicolumn{7}{|c|}{ Municípios } \\
\hline & Cáceres & $\begin{array}{c}\text { São José } \\
\text { dos Quatro } \\
\text { Marcos }\end{array}$ & $\begin{array}{l}\text { Pontes e } \\
\text { Lacerda }\end{array}$ & $\begin{array}{c}\text { Tangará da } \\
\text { Serra }\end{array}$ & Sinop & Colíder & Médias \\
\hline CNPA/96-1202 & $4.248,75$ & $3.237,50$ & $2.471,50$ & $1.861,00$ & $2.101,25$ & $2.575,50$ & $2.740,25$ \\
\hline BRS-201 & $4.595,00$ & $3.551,75$ & $2.001,25$ & $2.008,00$ & $2.251,00$ & $2.539,00$ & $2.824,33$ \\
\hline BRS CEDRO & $4.396,24$ & $3.950,25$ & $2.425,00$ & $2.091,50$ & $2.259,00$ & $2.370,75$ & $2.915,46$ \\
\hline DELTA OPAL & $4.256,25$ & $3.373,75$ & $2.065,00$ & $1.633,00$ & $2.221,25$ & $2.307,25$ & $2.642,75$ \\
\hline DP-4049 & $4.490,00$ & $3.478,00$ & $2.261,25$ & $2.133,00$ & $2.297,25$ & $2.497,75$ & $2.859,54$ \\
\hline IAC/97-86 & $5.113,64$ & $3.347,50$ & $2.371,25$ & $2.435,75$ & $2.465,25$ & $2.594,25$ & $3.054,60$ \\
\hline IPR-94 & $3.953,75$ & $3.619,50$ & $2.495,00$ & $2.255,25$ & $2.358,25$ & $2.755,25$ & $2.906,17$ \\
\hline IPR-96 & $4.501,24$ & $3.764,00$ & $2.102,50$ & $2.285,50$ & $2.334,50$ & $2.773,75$ & $2.960,25$ \\
\hline EPAMIG LIÇA & $3.253,75$ & $2.294,50$ & $2.173,75$ & $1.841,25$ & $2.258,50$ & $1.753,00$ & $2.262,46$ \\
\hline FMT-SATURNO & $3.886,06$ & $3.662,75$ & $2.007,50$ & $2.055,75$ & $2.197,25$ & $2.709,75$ & $2.753,18$ \\
\hline BRS-97/1682 & $4.159,39$ & $3.084,75$ & $2.043,75$ & $1.872,00$ & $1.960,00$ & $2.575,25$ & $2.615,86$ \\
\hline ITA-90 & $3.934,57$ & $2.989,25$ & $2.122,50$ & $2.033,25$ & $2.215,25$ & $2.482,75$ & $2.629,59$ \\
\hline QM TRATAMENTOS & $737.737,01^{\star *}$ & $758.206,31^{\star *}$ & $128.295,60 \mathrm{~ns}$ & $196.800,79 *$ & $64.753,02 \mathrm{~ns}$ & $297.332,02^{\star *}$ & - \\
\hline QM RESÍDUO & $135.736,33$ & $80.380,14$ & $85.895,47$ & $72.059,82$ & $42.721,25$ & $86.360,62$ & - \\
\hline MÉDIAS & $4.231,31$ & $3.362,79$ & $2.207,19$ & $2.042,10$ & $2.243,23$ & $2.494,52$ & - \\
\hline $\mathrm{CV}(\%)$ & 8,71 & 8,43 & 13,27 & 13,14 & 9,21 & 11,78 & 10,76 \\
\hline
\end{tabular}


Anexo $\mathrm{H}$. Correlação fenotípica entre médias de tratamentos para a produtividade de algodão em caroço $(\mathrm{kg} / \mathrm{ha})$ dos tratamentos entre os locais, obtidos dos experimentos do Ensaio Nacional de algodoeiro herbáceo no sistema de agricultura empresarial e familiar, nos anos agrícolas 1998/99, 1999/00 e 2000/01

\begin{tabular}{lcc}
\hline Município & Município & Correlaçã \\
\hline Ano 1998/99 - Empresarial & & \\
Rondonópolis & Alto Taquari & 0,2593 \\
Rondonópolis & Pedra Preta & 0,8334 \\
Rondonópolis & Campo Verde & 0,2400 \\
Rondonópolis & P. do Leste & $-0,0222$ \\
Rondonópolis & Nova Mutum & $-0,0544$ \\
Rondonópolis & C. N. Parecis & 0,2033 \\
Rondonópolis & Sapezal & 0,1211 \\
Rondonópolis & L. R. Verde & 0,0084 \\
Alto Taquari & Pedra Preta & 0,6051 \\
Alto Taquari & Campo Verde & 0,2137 \\
Alto Taquari & P. do Leste & 0,5629 \\
Alto Taquari & Nova Mutum & 0,3809 \\
Alto Taquari & C. N. Parecis & 0,1034 \\
Alto Taquari & Sapezal & 0,2172 \\
Alto Taquari & L. R. Verde & 0,1840 \\
Pedra Preta & Campo Verde & 0,3331 \\
Pedra Preta & P. do Leste & 0,2585 \\
Pedra Preta & Nova Mutum & 0,1000 \\
Pedra Preta & C. N. Parecis & 0,1211 \\
Pedra Preta & Sapezal & 0,0414 \\
Pedra Preta & L. R. Verde & 0,0580 \\
C. Verde & P. do Leste & 0,5124 \\
C. Verde & Nova Mutum & 0,3804 \\
C. Verde & C. N. Parecis & 0,1609 \\
C. Verde & Sapezal & 0,4112 \\
C. Verde & L. R. Verde & 0,3238 \\
P. do Leste & Nova Mutum & 0,4320 \\
P. do Leste & C. N. Parecis & $-0,0333$ \\
P. do Leste & Sapezal & 0,4737 \\
P. do Leste & L. R. Verde & 0,5166 \\
Nova Mutum & C. N. Parecis & 0,6321
\end{tabular}


Anexo H. Correlação fenotípica entre médias de tratamentos para a da produtividade de algodão em caroço $(\mathrm{kg} / \mathrm{ha})$ dos tratamentos entre os locais, obtidos dos experimentos do Ensaio Nacional de algodoeiro herbáceo no sistema de agricultura empresarial e familiar, nos anos agrícolas 1998/99, 1999/00 e 2000/01

\begin{tabular}{|c|c|c|}
\hline Município & Município & Correlação \\
\hline Nova Mutum & Sapezal & 0,1208 \\
\hline Nova Mutum & L. R. Verde & 0,7760 \\
\hline C. N. Parecis & Sapezal & $-0,3563$ \\
\hline C. N. Parecis & L. R. Verde & 0,6465 \\
\hline Sapezal & L. R. Verde & $-0,1118$ \\
\hline \multicolumn{3}{|c|}{ Ano 1999/00 - Empresarial } \\
\hline Rondonópolis & Itiquira & 0,6180 \\
\hline Rondonópolis & Pedra Preta & 0,2947 \\
\hline Rondonópolis & Alto Taquari & 0,5825 \\
\hline Rondonópolis & Campo Verde & 0,2127 \\
\hline Rondonópolis & P. do Leste & 0,4345 \\
\hline Rondonópolis & C. N. Parecis 1 & 0,1844 \\
\hline Rondonópolis & C. N. Parecis 2 & 0,1432 \\
\hline Rondonópolis & Sapezal & 0,6388 \\
\hline Rondonópolis & Nova Mutum & 0,4586 \\
\hline Rondonópolis & L. R. Verde & 0,6811 \\
\hline Rondonópolis & Sorriso & 0,3651 \\
\hline Itiquira & Pedra Preta & 0,8195 \\
\hline Itiquira & Alto Taquari & 0,8904 \\
\hline Itiquira & Campo Verde & 0,7152 \\
\hline Itiquira & P. do Leste & 0,5078 \\
\hline Itiquira & C. N. Parecis 1 & 0,5331 \\
\hline Itiquira & C. N. Parecis 2 & 0,2198 \\
\hline Itiquira & Sapezal & 0,6762 \\
\hline Itiquira & Nova Mutum & 0,3542 \\
\hline Itiquira & L. R. Verde & 0,8104 \\
\hline Itiquira & Sorriso & 0,3968 \\
\hline Pedra Preta & Alto Taquari & 0,8455 \\
\hline Pedra Preta & Campo Verde & 0,8314 \\
\hline Pedra Preta & P. do Leste & 0,7017 \\
\hline Pedra Preta & C. N. Parecis 1 & 0,7350 \\
\hline Pedra Preta & C. N. Parecis 2 & 0,4077 \\
\hline Pedra Preta & Sapezal & 0,6134 \\
\hline Pedra Preta & Nova Mutum & 0,4367 \\
\hline Pedra Preta & L. R. Verde & 0,7022 \\
\hline
\end{tabular}


Anexo H. Correlação fenotípica entre médias de tratamentos para a da produtividade de algodão em caroço $(\mathrm{kg} / \mathrm{ha})$ dos tratamentos entre os locais, obtidos dos experimentos do Ensaio Nacional de algodoeiro herbáceo no sistema de agricultura empresarial e familiar, nos anos agrícolas 1998/99, 1999/00 e 2000/01

\begin{tabular}{|c|c|c|}
\hline Município & Município & Correlação \\
\hline Pedra Preta & Sorriso & 0,6376 \\
\hline Alto Taquari & Campo Verde & 0,8195 \\
\hline Alto Taquari & P. do Leste & 0,6779 \\
\hline Alto Taquari & C. N. Parecis 1 & 0,5977 \\
\hline Alto Taquari & C. N. Parecis 2 & 0,3941 \\
\hline Alto Taquari & Sapezal & 0,6584 \\
\hline Alto Taquari & Nova Mutum & 0,2866 \\
\hline Alto Taquari & L. R. Verde & 0,7291 \\
\hline Alto Taquari & Sorriso & 0,4663 \\
\hline Campo Verde & P. do Leste & 0,6923 \\
\hline Campo Verde & C. N. Parecis 1 & 0,6181 \\
\hline Campo Verde & C. N. Parecis 2 & 0,5029 \\
\hline Campo Verde & Sapezal & 0,6092 \\
\hline Campo Verde & Nova Mutum & 0,3527 \\
\hline Campo Verde & L. R. Verde & 0,7073 \\
\hline Campo Verde & Sorriso & 0,6216 \\
\hline P. do Leste & C. N. Parecis 1 & 0,5954 \\
\hline P. do Leste & C. N. Parecis 2 & 0,5513 \\
\hline P. do Leste & Sapezal & 0,5366 \\
\hline P. do Leste & Nova Mutum & 0,5622 \\
\hline P. do Leste & L. R. Verde & 0,6844 \\
\hline P. do Leste & Sorriso & 0,8349 \\
\hline C. N. Parecis 1 & C. N. Parecis 2 & 0,7924 \\
\hline C. N. Parecis 1 & Sapezal & 0,5004 \\
\hline C. N. Parecis 1 & Nova Mutum & 0,6072 \\
\hline C. N. Parecis 1 & L. R. Verde & 0,5464 \\
\hline C. N. Parecis 1 & Sorriso & 0,5893 \\
\hline C. N. Parecis 2 & Sapezal & 0,5468 \\
\hline C. N. Parecis 2 & Nova Mutum & 0,5988 \\
\hline C. N. Parecis 2 & L. R. Verde & 0,4606 \\
\hline C. N. Parecis 2 & Sorriso & 0,6571 \\
\hline Sapezal & Nova Mutum & 0,7706 \\
\hline Sapezal & L. R. Verde & 0,8748 \\
\hline Sapezal & Sorriso & 0,7070 \\
\hline Nova Mutum & L. R. Verde & 0,7163 \\
\hline Nova Mutum & Sorriso & 0,7923 \\
\hline
\end{tabular}


Anexo H. Correlação fenotípica entre médias de tratamentos para a da produtividade de algodão em caroço $(\mathrm{kg} / \mathrm{ha})$ dos tratamentos entre os locais, obtidos dos experimentos do Ensaio Nacional de algodoeiro herbáceo no sistema de agricultura empresarial e familiar, nos anos agrícolas 1998/99, 1999/00 e $2000 / 01$

\begin{tabular}{lcc}
\hline Município & Município & Correlação \\
L. R. Verde & Sorriso & 0,7309 \\
Ano 2000/01 - Empresarial & & \\
Rondonópolis & Campo Verde & 0,4568 \\
Rondonópolis & Pedra Preta & 0,2442 \\
Rondonópolis & Sapezal & 0,0568 \\
Rondonópolis & Sorriso & 0,7241 \\
Rondonópolis & P. do Leste & 0,5833 \\
Rondonópolis & N. S. Joaquim & 0,4805 \\
Rondonópolis & C. N. Parecis & 0,6381 \\
Rondonópolis & L. R. Verde & $-0,0136$ \\
Campo Verde & Pedra Preta & 0,7432 \\
Campo Verde & Sapezal & 0,0179 \\
Campo Verde & Sorriso & 0,8424 \\
Campo Verde & P. do Leste & 0,5749 \\
Campo Verde & N. S. Joaquim & 0,9038 \\
Campo Verde & C. N. Parecis & 0,4314 \\
Campo Verde & L. R. Verde & 0,0458 \\
Pedra Preta & Sapezal & $-0,3994$ \\
Pedra Preta & Sorriso & 0,6965 \\
Pedra Preta & P. do Leste & 0,4792 \\
Pedra Preta & N. S. Joaquim & 0,7349 \\
Pedra Preta & C. N. Parecis & 0,5177 \\
Pedra Preta & L. R. Verde & 0,0178 \\
Sapezal & Sorriso & $-0,0986$ \\
Sapezal & P. do Leste & $-0,1586$ \\
Sapezal & N. S. Joaquim & $-0,0482$ \\
Sapezal & C. N. Parecis & $-0,4252$ \\
Sapezal & L. R. Verde & 0,0944 \\
Sorriso & P. do Leste & 0,6936 \\
Sorriso & N. S. Joaquim & 0,9282 \\
Sorriso & C. N. Parecis & 0,7605 \\
Sorriso & L. R. Verde & 0,0391 \\
P. do Leste & N. S. Joaquim & 0,6737 \\
& & \\
& &
\end{tabular}


Anexo H. Correlação fenotípica entre médias de tratamentos para a da produtividade de algodão em caroço $(\mathrm{kg} / \mathrm{ha})$ dos tratamentos entre os locais, obtidos dos experimentos do Ensaio Nacional de algodoeiro herbáceo no sistema de agricultura empresarial e familiar, nos anos agrícolas 1998/99, 1999/00 e $2000 / 01$

\begin{tabular}{l}
\hline Município \\
\hline P. do Leste \\
P. do Leste \\
N. S. Joaquim \\
N. S. Joaquim \\
C. N. Parecis \\
Ano 1998/99 - Fa \\
Cáceres \\
Cáceres \\
Cáceres \\
Cáceres \\
Sinop \\
Sinop \\
Sinop \\
T. da Serra \\
T. da Serra \\
P. e Lacerda \\
Ano 1999/00 - Fam \\
Cáceres \\
Cáceres \\
Cáceres \\
Cáceres \\
S. J. Q. Marcos \\
S. J. Q. Marcos \\
S. J. Q. Marcos \\
G. d'Oeste \\
G. d'Oeste \\
P. e Lacerda
\end{tabular}

Município

C. N. Parecis

L. R. Verde

C. N. Parecis

L. R. Verde

L. R. Verde

Sinop

T. da Serra

P. e Lacerda

S. J. Q. Marcos

T. da Serra

P. e Lacerda

S. J. Q. Marcos

P. e Lacerda

S. J. Q. Marcos

S. J. Q. Marcos

S. J. Q. Marcos

G. d'Oeste

P. e Lacerda

Sinop

G. d'Oeste

P. e Lacerda

Sinop

P. e Lacerda

Sinop

Sinop

Ano 2000/01 - Familiar

Cáceres

Cáceres

Cáceres

Cáceres

Cáceres
S. J. Q. Marcos $\quad 0,5854$

P. e Lacerda $\quad 0,1612$

T. da Serra $\quad 0,5049$

Sinop $\quad 0,3647$

Colíder

0,5315
0,6850

$-0,2387$

0,5726

$-0,0579$

0,2204

0,5252

0,3868

0,2776

$-0,5185$

0,1772

0,4070

$-0,0109$

0,5101

0,0490

0,5101

$-0,2365$

$-0,5870$

0,4110

0,5531

0,4133

$-0,3083$

$-0,0230$

$-0,5201$

0,0541

0,2624 
Anexo H. Correlação fenotípica entre médias de tratamentos para a da produtividade de algodão em caroço $(\mathrm{kg} / \mathrm{ha})$ dos tratamentos entre os locais, obtidos dos experimentos do Ensaio Nacional de algodoeiro herbáceo no sistema de agricultura empresarial e familiar, nos anos agrícolas 1998/99, 1999/00 e $2000 / 01$

\begin{tabular}{lcc}
\hline Município & Município & Correlação \\
\hline S. J. Q. Marcos & P. e Lacerda & 0,1609 \\
S. J. Q. Marcos & T. da Serra & 0,4395 \\
S. J. Q. Marcos & Sinop & 0,2566 \\
S. J. Q. Marcos & Colíder & 0,7199 \\
P. e Lacerda & T. da Serra & 0,3669 \\
P. e Lacerda & Sinop & 0,3378 \\
P. e Lacerda & Colíder & 0,0789 \\
T. da Serra & Sinop & 0,7054 \\
T. da Serra & Colíder & 0,5346 \\
Sinop & Colíder & 0,0656 \\
\hline
\end{tabular}




\section{REFERÊNCIAS BIBLIOGRÁFICAS}

ALLARD, R. W. Princípios do melhoramento genético das plantas. São Paulo: Edgard Blucher. 1966. 381p.

ALLARD, R. W.; BRADSHAW, A. D. Implications of genotype environmental interactions in applied plant breeding. Crop Science, v.4, p.503-508, 1964.

ANNICCHIARICO, P. Cultivar adaptation and recommendation form alfalfa trial in Northem Italy. Journal of Genetics \& Breeding, n.1, p.269-278, 1992. ANUÁRIO BRASILEIRO DO ALGODÃO. Rondonópolis: Fundação MT/Gazeta Grupo de Comunicações, 2001. 143 p.

ARIAS, E. R. A. Adaptabilidade e estabilidade das cultivares de milho avaliadas no estado de Mato Grosso do Sul e avanço genético obtido no período de 1986/1987 a 1993/1994. Lavras, 1996. 118p. Tese (Doutorado) Universidade Federal de Lavras.

ASSOCIAÇÃO MATO-GROSSENSE DE PRODUTORES DE ALGODÃO. Estatísticas. http://www.mtcotton.org.br/estatísticas_1.asp (7 out. 2003). BECKER, H. C. Correlations among some statistical measures of phenotypic stability. Euphytica, v.30, p.835-840, 1981.

BOLONHEZI. A. C.; FREITAS, H. A. de S.; DElAVALE, F. G.; JUSTI, M. M.; FUZATTO, M.; CIA, E. Desempenho de variedades de algodão herbáceoensaio nacional: características econômicas e retenção de estruturas reprodutivas. In: CONGRESSO BRASILEIRO DE ALGODÃO, Ribeirão Preto, 1999. Anais. Campina Grande: Embrapa Algodão, 1999, 716p.

BONATO, E. R. Estabilidade fenotípica da produção de grãos de dez cultivares de soja [Glycine $\max (L)$ Merril] nas condições do Rio Grande do Sul. 
CARVALHO, L. H.; CHIAVEGATO, E. J. A cultura do algodão no Brasil: fatores que afetam a produtividade. In: CIA, E.; FREIRE, E. C.; SANTOS, W. J. Cultura do algodoeiro. Piracicaba: Potafós, 1999. p.1-8.

CARVALHO, L. P. de.; COSTA, J. N. da; SANTOS, J. W. dos; ANDRADE, f. p. de. Adaptabilidade e estabilidade em cultivares de algodoeiro herbáceo. Pesquisa Agropecuária Brasileira, Brasília. v.30, n.2, p.207-213, 1995.

CAVALERI, P. A.; GRIDI-PAPP, I.L. Algodão. In: FURLANI, A. M. C.; VIEGAS, G. P. (Ed.) O melhoramento de plantas no Instituto de Campinas.

Campinas: Instituto Agronômico de Campinas, v.1, p.13-27, 1993.

CHAVES, J. L. Interação de cultivares com ambientes. In: NASS, L.; VALOIS, A. C. C.; MELO, I. S. de; VALADARES, M. C. (Ed.) Recursos genéticos e melhoramento - plantas. Rondonópolis: Fundação MT, 2001. p.673-713.

CIA, E.; FUZATTO, M. G.; KONDO, J. I.; SABINO, N. P.; CHIAVEGATO, E. J.; ERISMANN, N. de M.; CARVALHO, L. H.; BOLONHEZI, D.; FOLTRAN, D. E.; KASAI, F. S.; BORTOLetTO, N.; GALlO, P. B.; RECCO, P. C.; ROSSETO, R. Comportamento de cultivares e linhagens de algodoeiro no Estado de São Paulo: ano agrícola 2000/01 (compact disc). In: CONGRESSO BRASILEIRO DE ALGODÃO, 4., Goiânia. 2003. Anais. Goiânia: Embrapa-Algodão, 2003.

CLAY, R. E.; ALLARD, R. W. A comparison of the performance of homogeneous and heterogeneous barley populations. Crop Science, v.9, n.4, p. 407-412, 1969.

CROSSA, J. Statiscal analysis of multilocation trials. Advance in Agronomy, v.44, p.55-85, 1990.

CRUZ, C. D. Programa GENES: aplicativo computacional em genética e estatística. Viçosa: UFV, 2001. 648p.

CRUZ, C. D.; CARNEIRO, P. C. S. Modelos biométricos aplicados ao melhoramento genético. Viçosa: UFV, 2003. 585p.

CRUZ, C. D.; REGAZZI, A. J. Modelos biométricos aplicados ao melhoramento genético. Viçosa: UFV, 2001. 390p. 
CRUZ, C. D.; TORRES, R. da A.; VENCOVSKY, R. Na alternative approach to the stability analysis proposed by Silva and Barreto. Revista Brasileira de Genética, v.12, n.3, p.567-580, 1989.

DAVIDE, A. C. Avaliação da adaptabilidade e da estabilidade fenotípica de progênies de Eucalyptus pellita F. Muell, introduzidas a Austrália. Curitiba, 1992. 114p. Tese (Doutorado) - Universidade Federal do Paraná.

DUARTE, J. B. Estudo da adaptabilidade e estabilidade fenotípica em linhagens e cultivares de feijão mulatinho (Phaseolus vulgaris L.). Piracicaba. 1988. 155p. Dissertação (Doutorado) - Escola Superior de Agricultura "Luiz de Queiroz", Universidade de São Paulo.

EBERHART, S. A.; RUSSELL, W. A. Stability parameters for comparing varieties. Crop Science, v. 6, n.1, p.36-40, 1966.

EMPRESA BRASILEIRA DE PESQUISA AGROPECUÁRIA. Melhoramento do algodoeiro na Embrapa - Algodão. http://algodao.cnpa.embrapa.br/ (13 Mar. 2003)

EMPRESA MATOGROSSENSE DE PESQUISA, ASSITÊNCIA TÉCNICA E EXTENSÃO RURAL. Diretrizes técnicas: algodão região cerrado. Cuiabá: EMPAER, 1992, 48p. 2v.

EMPRESA MATOGROSSENSE DE PESQUISA, ASSITÊNCIA TÉCNICA E EXTENSÃO RURAL. Diretrizes técnicas: algodão região cerrado. Cuiabá: EMPAER, 1997, 58p. 5v.

ESTEFANEL, V.; PIGNATARO, I. A. B.; STORK, L. Avaliação do coeficiente de variação de experimentos de algumas culturas agrícolas. In: SIMPÓSIO DE ESTATíSTICA APLICADA À EXPERIMENTAÇÃO AGRONÔMICA, Londrina, 1987.

FALCONER, D. S. Introdução à genética quantitativa. Trad. de M. de Almeida e J. C. Silva. Viçosa: UFV, 1987. 279p.

FARIAS, F. J. C. Parâmetros de estabilidade em cultivares de algodoeiro herbáceo (Gossypium hirsutum L. r. latifolium Hutch.) avaliadas na região Nordeste no período de 1981 a 1992. Lavras. 1995. 89p. Dissertação (Mestrado) - Universidade Federal de Lavras. 
FARIAS, F. J. C.; FREIRE, E. C.; CARVALHO, L. P. de.; ARANTES, E. M.; OLIVEIRA, L. C. de. Estabilidade adaptabilidade de cultivares de algodoeiro herbáceo no estado do Mato Grosso. Campina Grande: EMBRAPA-ALGODÃO, 1996. 4p. (Pesquisa em andamento, 29)

FARIAS, F. J. C.; RAMALHO, M. A. P.; CARVALHO, L. P.; MOREIRA, J. A. N.; COSTA, J. N. Repetibilidade nos parâmetros de estabilidade na cultura do algodoeiro herbáceo. Pesquisa Agropecuária Brasileira, v.33, n.4, p.457461, 1998.

FARIAS, F. J. C.; FREIRE, E. C.; LAMAS. F.; ANDRADE, D. F. A.; CIA, E. Avaliação do Ensaio nacional de Cultivares de algodoeiro herbáceo do Mato Grosso e Mato Grosso do Sul. In: CONGRESSO BRASILEIRO DE ALGODÃO, Campo Grande, 2001. Anais. Campina Grande: Embrapa Algodão; Campo Grande: UFMS; Dourados: Embrapa Agropecuária Oeste, 2001, 648p.

FINLAY, K. W.; WILKINSON, G. N. The analysis of adaptation in a plant breeding programme. Australian Journal of Agricultural Research, v.14, p.742-754, 1963.

FORTUNA, P.; LAMAS, F. M.; FERRAZ, C. T. Avaliação de linhagens e cultivares de algodoeiro em Mato Grosso do Sul. In: CONGRESSO BRASILEIRO DE ALGODÃO, 2., Ribeirão Preto, 1999. Anais. Campina Grande: Embrapa-Algodão, 1999. p. 591-594.

FREEMAN, G. H. PERKINS, J. M. Enviromental and genotype-environmental components of variability. Relations between genotypes grow in different environments and measures of these environments. Heredity, v.27, p.15-23, 1971.

FREIRE, E. C. Relatório de atividades desenvolvidas durante o ano de 1996 na execução do convênio EMBRAPA/ITANORTE/EMPAERMT/FUNDAÇÃO MT. Campina Grande: Embrapa-Algodão, 1996. 29p.

FREIRE, E. C.; COSTA, J. N. da. Objetivos e métodos utilizados nos programas de melhoramento do algodão no Brasil. In: BELTRÃO, N. E. de M. O Agronegócio do algodão no Brasil. Brasília: Embrapa, 1999. p.271-288. 
FREIRE, E. C.; FARIAS, F. J. C. Cultivares de algodão para o Centro-Oeste. Algodão: tecnologia de produção. Dourados: Embrapa Agropecuária Oeste; Campina Grande: Embrapa-Algodão, 2001. p.159-179.

FREIRE, E. C.; FARIAS, F. J. C.; FERRAZ, C. T. Cultivares. Algodão: informações técnicas. Dourados: Embrapa Agropecuária Oeste; Campina Grande: Embrapa-Algodão, 1998. p.18-27. (Circular Técnica, 7).

FREIRE, E. C.; SANTOS, J. W. dos; ANDRADE, F. P.; VIDAL NETO, F. das C.; LIRA, M. A.; RIBEIRO, J. L. Adaptabilidade e estabilidade de cultivares de gergelim. Pesquisa Agropecuária Brasileira, v.29, n.6, p.891-900, 1994.

FREITAS, H. A. de S.; BAZANINI, G. C.; SILVA, E. A.; TOBAL, F. M.; BOLONHEZI, A. C.; FUZATTO, M. G.; CIA, E. Avaliação de variedades e linhagens de algodoeiro herbáceo (Gossypium hirsutum raça latifolium): características agronômicas e retenção de estruturas reprodutivas. In: CONGRESSO BRASILEIRO DE ALGODÃO, Campo Grande, 2001. Anais. Campina Grande: Embrapa Algodão; Campo Grande: UFMS; Dourados: Embrapa Agropecuária Oeste, 2001, 648p.

Fryxell, P.A. 1992. A revised taxonomic interpretation of Gossypium. Rheedea n.2, p.108-165, 1992.

FUNDAÇÃO DE APOIO À PESQUISA AGROPECUÁRIA DE MATO GROSSO. Algodão - safra 95/96: resultados preliminares. Rondonópolis: Fundação MT, 1996. 47p. (Boletim de Pesquisa, 01)

FUZATTO, M. G. Melhoramento Genético do Algodoeiro. In: CIA, E.; FREIRE, E. C.; SANTOS, W. J. dos (Ed.) Cultura do Algodoeiro. Piracicaba: Potafos, 1999. 286p.

FUZATTO, M. G.; CIA, E.; CHIAVEGATO, E. J. Estabilidade de produção de cultivares de algodoeiro em face da ocorrência de doenças. Bragantia, v.53, p.47-52, 1994.

GRIDI-PAPP, I. L. FUZATTO, M. G.; CAVALERI, P. A. ; CHIAVEGATO, E. J.; FERRAZ, C. A. M.; SABINO, N. P.; KONDO, J. G.; SOAVE, J.; BORTOLETTO, N. Melhoramento do algodoeiro no Estado de São Paulo: obtenção da variedade IAC 18. Bragantia, v.43, p.405-423, 1985. 
JOWETT, D. Yield stability parameters for sorghum in East Africa. Crop Science. Madison, v.12, n.3, p.314-317, 1972.

LANGER, I.; FREY, K. J.; BAILEY, T. Associations among productivity, production response and stability indexes in oat varieties. Euphytica, v.28, p.17-24, 1979.

LEE, J. A. Cotton as world crop. In: KOHEL, R. J.; LEWIS, C. F. (Ed.) Cotton. Madison: ASA, 1984. p.1-25.

LIN, C. S.; BINNS, M. R. A method of analyzing cultivars $x$ location $x$ year experiments: a new stability parameter. Theoretical Applied Genetics, v.76, n.3, p.425-430, 1988.

LIN, C. S.; BURS, M. R.; LEFKOUITCH, L. P. Stability analysis: where do we stand? Crop Science. n.26, p.894-900, 1986.

MACHADO, J. R. de A.; PENNA, J. C. V.; SANTOS, P. G.; FALLIERI, J.; LANZA, M. A. Estabilidade de genótipos de algodoeiro para produtividade de pluma em $\mathrm{kg} \mathrm{ha}^{-1}$ (compact disc). In: CONGRESSO BRASILEIRO DE ALGODÃO, 4., Goiânia, 2003. Anais. Goiânia: Embrapa-Algodão, 2003.

MACHADO, J. R. DE A. PENNA, J. C. V. FALLIERI, J.; MELO, P. G.; LANZA, M. Adaptabilidade e estabilidade de cultivares de algodoeiro (Gossypium hirsutum L.) em Minas Gerais (compact disc). In: CONGRESSO BRASILEIRO DE ALGODÃO, 3., Campo Grande. 2001. Anais. Campo Grande: Embrapa-Algodão/UFMS, 2001.

MANGUEIRA, B. Taxa de alogamia na cultura do algodoeiro "mocó". Recife: IPA, 1971, 22p. (Boletim Técnico, 50).

MARIOTTI, J. A. OYARZABAL, E. S.; OSA, J. M.; BULACIO, A. N. R; ALMADA, G. H. Análises de estabilidad y adaptabilidad de cultivares de caña de azúcar. Interacción dentro de una localidad experimental. Revista Agronómica del Noroeste Argentino, v.13, n.1/4, p.105-127, 1976.

MARSHALL, D. R.; BROWN, A. H. D. Stability of performance of mixtures and multilines. Euphytica, v.22, n.2, p.405-412, 1973. 
MELO FILHO, G. A. de. Sistema de produção de algodão no Cerrado da Região Centro-Oeste do Brasil (compact disc). In: CONGRESSO BRASILEIRO DE ALGODÃO, 4., Goiânia, 2003. Anais. Goiânia: Embrapa-Algodão, 2003.

MORAIS, O. P. Adaptabilidade, estabilidade de comportamento e correlações fenotípicas, genotípicas e de ambiente em variedades e linhagens de arroz (Oryza sativa L). Viçosa. 1980. 70p. Dissertação (Mestrado) - Universidade Federal de Viçosa.

MOREIRA, J. de A.N.; SILVA, N.M.; MEDEIROS, L.C.; SANTANA, J.C.F. Estabilidade de comportamento em cultivares de algodoeiro herbáceo em diversos ambientes. Campina Grande: Embrapa-CNPA,1983. 58p. (Embrapa-CNPA. Boletim de Pesquisa,13).

MORESCO, E. R. Progresso genético no melhoramento do algodoeiro no Estado do Mato Grosso. Piracicaba. 2003. 78p. Dissertação (Doutorado) Escola Superior de Agricultura "Luiz de Queiroz", Universidade de São Paulo.

OLIVEIRA, A. C. Comparação de alguns métodos de determinação da estabilidade em plantas cultivadas. Brasília. 1976. 64p. Tese (Mestrado) Universidade de Brasília.

PARO, H. A história do algodão em Mato Grosso. Cuiabá: EMPAER. 2000. $46 p$.

PENNA, J. C. V. Melhoramento do algodão. In: BORÉM, A. Melhoramento de espécies cultivadas. Viçosa: UFV, 1999, p.15- 50.

PHINTUS, M. J. Estimative of genotypic value: a proposed method. Euphytica, v.22, n.3, n.1,p.121-123, 1973.

PLAISTED, R. L.; PETERSON, L. C. A technique for evaluating the ability of selections to yield consistently in different locations or seasons. American Potato Journal. v.36, n.2, p.381-385, 1959.

RAMALHO, M. A. P.; SANTOS, J. B. dos; ZIMMERMANN, M. J. DE O.; Genética quantitativa de plantas autógamas: aplicações ao melhoramento do feijoeiro. Goiânia: UFG, 1993. 271p. 
RICHETTI, A.; MELO FILHO, G. A. de; Algodão: informações técnicas. Dourados: Embrapa-CPAO; Campina Grande: Embrapa-Algodão, 1998. 25p. (Circular Técnica, 7).

RIBEIRO, J. L.; FREIRE, E. C.; FARIAS, F.J. C.; ANDRADE, F. P.; COSTA, J. N. da; MEDEIROS, J. da C.; SANTANA, J. C. F. de.; Cultivares de algodoeiro herbáceo recomendadas para os cerrados do meio-norte do Brasil (compact disc). In: CONGRESSO BRASILEIRO DE ALGODÃO, 4., Goiânia, 2003. Anais. Goiânia: Embrapa-Algodão, 2003.

ROCHA, M. de M. Seleção de linhagens experimentais de soja para adaptabilidade e estabilidade fenotípica. Piracicaba, 2002. 173p. Tese (Doutorado) - Escola Superior de Agricultura "Luiz de Queiroz", Universidade de São Paulo.

ROSSE, L. N. Modelo de regressão não-linear aplicado na avaliação da estabilidade fenotípica em plantas. Piracicaba, 1999. 179p. Tese (Doutorado) - Escola Superior de Agricultura "Luiz de Queiroz", Universidade de São Paulo.

SANTANA, J. C. F. de; CAVAlCANTI, F. B.; SANTOS, E. O. Parâmetros de estabilidade na comparação de cultivares de algodoeiro herbáceo. Pesquisa Agropecuária Brasileira, v.18, n.3, p.261-267, 1983.

SANTOS, E. O.; FREIRE, E. C. Determinação da taxa de cruzamento em algodoeiro herbáceo. In: REUNIÃO NACIONAL DO ALGODÃO, Londrina, 1980. Resumos. Londrina: IAPAR/EMBRAPA, 1980. p.215.

SANTOS, J. B. dos. Estabilidade fenotípica de cultivares de feijão (Phaseolus vulgaris L.) nas condições do Sul de Minas Gerais. Piracicaba, 1980. 110p. Dissertação (Mestrado) - Escola Superior de Agricultura "Luiz de Queiroz", Universidade de São Paulo.

SAS Institute inc. SAS/STAT. SAS user's guide for windows environment. 8.2 ed. Cary, SAS Insitute Inc., 1999.

SHUKLA, G. K. Some statistical aspects of partitioning genotype-byenviromenment interaction model and stability estimates. Journal of 
Agricultural, Biological and Environmental Statistics, v.3, n.3, p.335-345, 1998.

SILVA, J. G.; BARRETO, J. N. Aplicação de regressão linear segmentada em estudos da interação cultivar $x$ ambiente. In: SIMPÓSIO DE ESTATÍSTICA APLICADA A EXPERIMENTAÇÃO AGRÍCOLA, Campinas, 1985. Anais. Campinas: Fundação Cargill, p.49-50.

SILVA, J. G. C. Análise de adaptabilidade através de regressão linear segmentada. 1. Fundamentos. Pesquisa Agropecuária Brasileira. v.30, n.4, p.435-438, 1995.

SOARES, A. A. Desempenho do melhoramento genético do arroz de sequeiro e irrigado na década de oitenta em Minas Gerais. Lavras. 1992. 187p. Tese (Doutorado) - Universidade Federal de Lavras.

SOBREIRA, E. S.; FARIAS, F. J. C.; GERALDI, I. O. Estabilidade de cultivares de algodoeiro herbáceo nas condições do cerrado (compact disc). In: CONGRESSO BRASILEIRO DE MELHORAMENTO DE PLANTAS, 2., Porto Seguro, 2003. Anais. Porto Seguro: SBMP, 2003.

TAI, G. C. C. Genotypic stability analysis and its application to potato regional trials. Crop Science, v.11, n.2, p.184-190, 1971.

TAKIZAWA, E. V. Desempenho de cultivares de algodão no Mato Grosso: safra 99/00 (compact disc). In: CONGRESSO INTERNACIONAL DO AGRONEGÓCIO DO ALGODÃO, Cuiabá, 2000. Anais. Cuiabá: Fundação MT, 2000.

TOLER, J. E. Patterns of genotypic perfomance over environmental arrays. Clemson, 1990. 154p. Thesis (Ph.D) - Clemson University

TORRES, R. A. A. Estudo do controle genético da estabilidade fenotípica de cultivares de milho (Zea mays L.). Piracicaba. 1988. 133p. Tese (Doutorado) - Escola Superior de Agricultura "Luiz de Queiroz". Universidade de São Paulo.

VENCOVSKY, R.; BARRIGA, P. Genética biométrica no fitomelhoramento. Ribeirão Preto: SBG, 1992. 496p. 
VENCOVSKY, R.; TORRES, R. A. A. Estabilidade geográfica e temporal de algumas cultivares de milho. In: CONGRESSO NACIONAL DE MILHO E SORGO, 16., Belo Horizonte, 1988. Anais. Belo Horizonte: Embrapa, CNPMS, 1988. p.294-300.

VERMA, M. M; G. S. CHACAL; MURTY, B. R. Limitations of conventional regression analysis: a proposed modification. Theorical and Applied Genetics, v.53, n.2, p.89-91, 1978.

VERONESI, J. A. Comparação de métodos e avaliação da adaptabilidade e estabilidade de comportamento de vinte cultivares de milho (Zea mays L.) em dez ambientes do estado de Minas Gerais. Viçosa, 1995. 70p. Tese (Mestrado). Universidade Federal de Viçosa.

VIDAL NETO, F. das C.; FREIRE, E. C.; ANDRADE, F. P. de; SANTOS, J. W. S.; ARAÚJO, G. P. Desempenho de cultivares e linhagens de algodoeiro herbáceo no Estado do Ceará (compact disc). In: CONGRESSO BRASILEIRO DE ALGODÃO, 4., Goiânia, 2003. Anais. Goiânia: EmbrapaAlgodão, 2003.

VIEIRA, R. de M.; MEDEIROS, A. A.; GUERRA, A. G.; SANTOS, F. C. dos; BARRETO, M. de F. P. Análise da produção e das propriedades tecnológicas da fibra do ensaio nacional de variedades de algodão, Ipangauça-RN, 1999 (compact disc). In: CONGRESSO BRASILEIRO DE ALGODÃO, Campo Grande, 2001. Anais. Campina Grande: Embrapa Algodão; Campo Grande: UFMS; Dourados: Embrapa Agropecuária Oeste, 2001.

WRICKE, G. Uber eine methode zur erfassung der Ökologischen streubreite in feldversuchen. Zeitschrift für PflanzenzÜchtung, v.47, n.1, p.92-96, 1962. WRICKE, G.; WEBER, E. W. Quantitative genetics and selections in plant breeeding. Berlin: Wlater de Gruyter, 1986, 406p.

ZOBEL, R. W.; MADISON, J. W.; GAUCH, H. G. Statistical analysis of a yield trial. Agronomy Journal, v.80, n.3, p.388-393, 1988. 